\title{
ERK-Mediated Phosphorylation of EZH2 Regulates HER2 Expression on Long-term Genistein-induced Acquired Endocrine Resistance in Estrogen- Receptor-Positive Breast Cancer Cells
}

\section{Chunyan Hu}

Nanjing Medical University

Qian Zhou

Nanjing Medical University

Bingmo Yang

Nanjing Medical University

Wei Xiao

Nanjing Medical University

Kailin Jiao

Nanjing Medical University

Keke Yang

Nanjing Medical University

Ming Zhou

Nanjing Medical University

Zhong Li ( $\sim$ Iz-ny@njmu.edu.cn )

Nanjing medical university

\section{Research}

Keywords: genistein, breast cancer, endocrine resistance, ERK, phospho-EZH2, H3K27me3, HER2

Posted Date: November 19th, 2020

DOI: https://doi.org/10.21203/rs.3.rs-108061/v1

License: (c) (1) This work is licensed under a Creative Commons Attribution 4.0 International License.

Read Full License 


\section{Abstract}

\section{Background}

Genistein, a soy isoflavones, is the most important phytoestrogens in typical oriental diet. Many studies have shown that genistein at lower concentrations promotes breast cancer cells growth through the estrogen receptor pathway. However, recent research has found that long-term consumption of low doses of genistein results in hormone-independent growth phenotypes of MCF-7 tumors, with increased expression of HER2. Overexpression of HER2 has been causally associated with endocrine therapy resistance in human breast cancer. The mechanism by which prolonged exposure to genistein leads to increased HER2 expression is unclear. Whether genistein-induced HER2 expression is the cause of endocrine resistance remains to be determined.

\section{Methods}

We selected the MCF-7 and T47D breast cancer cells model with higher ERa and lower HER2. It was investigated whether prolonged exposure to genistein induced TAM-sensitive breast cancer cells to TAMrefractory cells by increasing HER2 expression. Furthermore, it was explored whether HER2 expression and endocrine resistance were associated with EZH2.

Results

We found that genistein had estrogen-like effect and inhibited HER2 expression during short-term exposure. However, long-term exposure to genistein induced acquire endocrine resistance, because of increased expression of HER2. During long-term exposure to genistein, the continuous activation of ERK1/2 phosphorylated EZH2 at Ser21, resulting in a decrease of lysine 27 trimethylation. As H3K27me3 level decreased, the expression of IL- 6 and IL-8 increased, and HER2 level gradually increased, forming a feedback loop of ERK1/2 / EZH2/ IL-6 and IL-8 / HER2.

\section{Conclusions}

These findings indicated that high HER2 expression caused by EZH2 phosphorylation was an important mechanism of endocrine resistance. The study also provided a new insight for genistein-induced acquired endocrine resistance. For breast cancer patients, long-term use of soy supplements has potential health risk. Especially, monitoring dietary exposure to genistein is advisable when treated with tamoxifen.

\section{Background}

Approximately $70 \%$ of breast cancers express estrogen receptor a (ERa) and merit the use of endocrine therapies, such as the estrogen receptor (ER) antagonist tamoxifen (TAM) [1]. However, ER-positive breast cancer frequently acquires resistance to TAM after long-term treatment, which is a serious therapeutic problem $[2,3]$. 
Multiple mechanisms are responsible for the development of endocrine resistance. Compelling evidence suggests that the human epidermal growth factor receptor (HER) family plays a critical role in mediating endocrine therapy resistance [4-8]. The amplification of the HER2 locus can overcome the growth inhibitory effects imposed by TAM in ER-positive breast cancers [9]. The mechanism by which HER2 overexpression mediates TAM resistance is the crosstalk between ERa and HER2 initiates intracellular kinase cascades, such as MAPK signaling, promoting growth and progression in breast cancer cells, negating the inhibitory effects of TAM [10].

Phytoestrogens are compounds derived from plants that have estrogenic properties and are abundant in the human diet, particularly Soy. Genistein (GE), a major phytoestrogen in soybeans found in processed foods, induces genomic ER signaling in the developing breast cancer [11, 12]. Although no studies in humans have been conducted, some studies have shown that genistein negates the inhibitory effects of TAM in breast cancer cell lines and animal models [13-15]. Previous study has demonstrated that longterm exposure to genistein leads to estrogen-independence growth in ER-positive breast tumors and results in increased expression of HER2 [16]. The exact cause of abnormal growth factor signaling caused by genistein is unknown. Genistein may not have estrogenic properties when acting on ERpositive breast cancer for a long time, may cause the development of acquired endocrine resistance in breast cancer, in which HER2 may play an important role.

Enhancer of zeste homolog 2 (EZH2) is frequently overexpressed in human bladder, breast, colon and prostate cancers [17]. Studies have shown that EZH2 specifically catalyzes trimethylation of histone $\mathrm{H} 3$ lysine 27 (H3K27me3), resulting in transcriptional repression and chromatin compaction [18-20]. Several studies have reported that epigenetic alterations are associated with endocrine resistance in breast cancer [21,22]. Although roles of EZH2 in driving cancer proliferation and invasion are extensively characterized [23, 24], few studies investigate the association of EZH2 with acquired endocrine resistance. Data from a study suggest that low H3K27me3 levels were significantly associated with aromatase inhibitor resistance in breast cancer patients [25]. Notably, genistein induced PI3K/AKT nongenomic ER signaling to phosphorylate and repress the histone methyltransferase EZH2. As a result, this signaling reduces levels of H3K27me3 in chromatin [26]. However, it is not clear whether inhibition of EZH2 histone methyltransferase activity is associated with increased HER2 expression and endocrine therapy resistance.

Therefore, we selected the MCF-7 and T47D breast cancer cells model with higher ERa and lower HER2. We have investigated whether prolonged exposure to genistein can induce TAM-sensitive breast cancer cells to TAM-refractory cells by increasing HER2 expression. During long-term exposure to Genistein, the phosphorylation of EZH2 and the levels of H3K27me3 were observed, and their effects on TAM sensitivity were evaluated. Furthermore, it was explored whether HER2 was physically associated with EZH2. The data reported here reveal genistein regulates TAM resistance through EZH2/ H3K27me3/HER2 axis in breast cancer.

\section{Methods}




\section{Reagents}

$\mathrm{E}_{2}$ and TAM were purchased from Sigma Aldrich (St. Louis, MO, USA). GSK-J4 was purchased from MedChemExpress (Monmouth Junction, NJ, USA). Genistein and U0126 were obtained from Beyotime Biotechnology (Nanjing, Jiangsu, China). Recombinant Human IL-6 and IL-8 were purchased from PeproTech (Cranbury, NJ, USA).

\section{Cell Culture}

Human breast cancer cell lines MCF-7, T47D were maintained in DMEM/F-12 medium (Yuanpei, Shanghai, China) supplemented with $10 \%$ fetal bovine serum (Biological Industries, Israel), 100 units $/ \mathrm{mL}$ penicillin (Beyotime, Nanjing, Jiangsu, China), $100 \mu \mathrm{g} / \mathrm{mL}$ streptomycin (Beyotime, Nanjing, Jiangsu, China), and $100 \mathrm{mM}$ nonessential amino acids (Life Technologies, Grand Island, NY, USA) at $37{ }^{\circ} \mathrm{C}$ in $5 \%$ $\mathrm{CO}_{2}$ atmosphere. To observe the short-term effects of $\mathrm{E}_{2}$ or genistein on cells, cells were switched to MEM medium without phenol red (Life Technologies, Grand Island, NY, USA) plus $5 \%$ charcoal-stripped fetal bovine serum (Biological Industries, Israel), supplemented with 100 units $/ \mathrm{mL}$ penicillin, $100 \mu \mathrm{g} / \mathrm{mL}$ streptomycin, $2 \mathrm{mM}$ L-glutamine and $100 \mathrm{mM}$ nonessential amino acids for at least 3 days before the experiments.

\section{RNA interference}

The 21-nucleotide duplex siRNAs for EZH2, HER2 and one negative control siRNA were synthesized by Santa Cruz (Dallas, Texas, USA). Transfection was carried out using Lipofectamine 3000 (Invitrogen, Carlsbad, CA, USA) following the manufacturer's instructions. Transfection efficiency was evaluated in every experiment by RT-qPCR 24 hours later to ensure that cells were transfected.

\section{Quantitative Real-Time RT-PCR (qPCR)}

Total RNA from the two cell lines was isolated using the TRIzol reagent (Invitrogen, Carlsbad, CA, USA) and reverse transcribed to cDNA using the ExScript RT reagent (Abm, Zhenjiang, Jiangsu, China). Realtime RT-PCR was performed using StepOnePlus Real Time PCR System (Roche Group, Basel, Switzerland) with specific primers for EZH2, HER2, IL-6, IL-8 and GAPDH expression was used to normalize for variance. Real-time fluorescence monitoring of the PCR products was performed with SYBR Green I fluorescent dye (Abm, Zhenjiang, Jiangsu, China). The expression levels of specific genes are reported as ratios of expression of GAPDH in the same master reaction.

\section{Western Blotting Analysis}

Cells were lysed with whole cell lysis buffer, frozen at $-80^{\circ} \mathrm{C}$ and thawed three times to rupture the cell membranes. Samples of the lysates were incubated for $30 \mathrm{~min}$ on ice to lyse the nuclei, and then centrifuged at $12,000 \mathrm{rpm}$ for $20 \mathrm{~min}$ at $4^{\circ} \mathrm{C}$. Equal amounts of protein $(20 \mu \mathrm{g})$ were subjected to western blot analysis. Western blotting was performed by standard procedures. 


\section{Proliferation Assay}

Breast cancer cells were seeded in 96-well plates (4000 cells/well). At the end of the cell treatment, cell proliferation was assayed using Cell Counting Kit-8(CCK-8) (Apexbio, Houston, TX, USA) as per the manufacturer's protocol.

\section{Statistical Analysis}

Experimental values are presented as mean \pm standard deviation (SD). At least three independent trials were performed for each experiment. Statistical analytical Methods and numbers of data points analyzed for each experiment are described in figure legends. Statistically significant analysis by two-way ANOVA with Sidak's multiple comparison test $(a=0.05)$ was performed in experiments graphed in Figure $1 a-c$, $4 d, 4 f, 5 e, 5 f$. One-way ANOVA with Dunnett's test $(a=0.05)$ was performed in experiments graphed in Figures $1 \mathrm{~g}$ and $5 \mathrm{~d}$. Independent two-samples t-test was performed in experiments graphed in Figures $1 \mathrm{~h}$, $1 \mathrm{i}, 4 \mathrm{c}, 4 \mathrm{e}, 5 \mathrm{a}-\mathrm{c}$. For all analyses, the $p$ values $<0.05$ were considered statistically significant.

\section{Results}

\section{Elevated HER2 promotes to genistein - induced acquired endocrine therapy resistance}

It has been shown that long-term consumption of low doses genistein promotes MCF-7 tumor growth and results in non-hormone dependent tumors with increased expression of HER2 [16]. Long-term TAM treatment also induces overexpression of HER2 as a resistance mechanism to hormonal therapy $[9,27]$. The different plasma levels of genistein were consistently observed in Asian and Western populations. For example, the plasma levels were about $0.02 \mu \mathrm{mol} / \mathrm{L}$ in English and $0.26 \mu \mathrm{mol} / \mathrm{L}$ in Japanese and Korean $[28,29]$. In this study, $1 \mu \mathrm{M}$ was selected as the study dose of genistein. Using ER-positive breast cancer cells, we investigated whether genistein induces resistance to endocrine therapy. After long-term (3 weeks) genistein exposure followed by a $24 \mathrm{~h}$ withdrawal, cells were treated with different concentrations of TAM for 48h. Compared with the parallel cells, the MCF-7 cells (Fig. 1a) and T47D cells (Fig. 1b) by prolong genistein stimulus and withdrawal showed resistance to TAM, while T47D cells treated with $E_{2}$ remained normal TAM sensitivity (Fig. 1c). Western blot analysis showed that HER2 levels decreased after genistein exposure for 24h (Fig. S1a and b), which was similar to $E_{2}$ (Fig. S1c). HER2 levels were significantly increased after 3 weeks of exposure to genistein in MCF-7 cells (Fig. 1d). During long-term genistein exposure, T47D cells were subjected to western blot analysis at 2 days, 1 week, 2 weeks, 3 weeks, respectively. HER2 expression decreased initially, then increased gradually. The levels were higher than that in the parental cells at 3 weeks (Fig. 1e and g). The HER2 levels increased substantially after TAM treatment for 24h (Fig. S1d) and further increased during prolonged TAM treatment (Fig. $1 \mathrm{f}$ and g). We investigated whether endocrine resistance is associated with up-regulation of the HER2. Under the action of HER2 siRNA (Fig. 1h), genistein-induced resistant cells recovered their sensitivity (Fig. 1i). All these results indicate that HER2 might play an important role in genistein-induced acquired endocrine resistance. 


\section{ERK1/2 signal activation caused by long-term exposure to genistein is associated with HER2 elevation}

The results of preclinical studies have indicated that acquired TAM resistance is associated with increased activities of ERK [30]. Genistein induces phosphorylation of ERK1/2 within a certain amount of time, and ERK activity starts at $3 \mathrm{~h}$ and peaks at $24 \mathrm{~h} \mathrm{[31].} \mathrm{In} \mathrm{the} \mathrm{present} \mathrm{study,} \mathrm{the} 24 \mathrm{~h}$ exposure of the T47D cells to genistein induced phosphorylation of ERK1/2 (Fig. S2a), as TAM did (Fig. S2b). During long-term genistein exposure, T47D cells were subjected to western blot analysis at 2 days, 1 week, 2 weeks, 3 weeks, respectively. Phosphorylation of ERK1/2 increased after 1 week (Fig. 2a). Phosphorylation of ERK1/2 increased at 3 weeks in MCF-7 cells (Fig. 2b). The results of TAM treatment were the same as those of long-term genistein exposure (Fig. 2c). We observed a similar trend in the changes of HER2 protein levels and ERK1/2 phosphorylation levels after long-term genistein exposure. MAP kinase displayed markedly increased activity in cell lines overexpressing HER2 [32]. In this study, Knockout of HER2 gene decreased phosphorylation of ERK1/2 (Fig. S2C). When MEK inhibitor U0126 treated T47D cells, inhibition of ERK1/2 phosphorylation down-regulated the levels of HER2 (Fig. S2d), genistein-induced (Fig. 2d) and TAM-induced (Fig. 2e) HER2 expression. These results indicate that activation of ERK1/2 signal caused by long-term exposure to genistein interacts with the expression of HER2.

\section{EZH2 phosphorylation at Ser21 increases and H3K27me3 levels reduce during long-term genistein exposure}

$\mathrm{EZH} 2$ is an estradiol-regulated gene and its promoter contains functional estrogen-response elements [33]. After TAM treatment for 24h, the mRNA and protein levels of EZH2 were down-regulated, as well as H3K27me3 levels (Fig.S3a). During long-term TAM treatment, EZH2 and H3K27me3 levels were also decreased (Fig. 3a). TAM inhibition of EZH2 expression may be caused by its antagonism against ER.

As a phytoestrogen, genistein promoted the expression of ERa target gene after 24h exposure (Fig.S3b). It also increased the levels of EZH2 and H3K27me3 in MCF-7 cells and T47D cells (Fig.S3c). During longterm genistein exposure, EZH2 protein levels increased at 2 days and 1 weeks, and fell back to the same level as the control at 2 weeks and 3 weeks. Remarkably, the levels of H3K27me3 increased first, and decreased at 2 weeks and 3 weeks (Fig. 3b). The expression of EZH2 decreased slightly and the levels of H3K27me3 also decreased at 3 weeks in MCF-7 cells (Fig. 3c). Collectively囚it seems highly likely that decreased trimethylation at $\mathrm{H} 3 \mathrm{~K} 27$ by long-term genistein exposure was not a result of decreased total levels of EZH2, because EZH2 levels remained unchanged or decreased slightly in response to long-term genistein.

Phosphorylation at Ser21 altered the affinity of EZH2 for its substrate, histone H3, which reduces EZH2 methyltransfease activity [34]. We hypothesized that genistein regulates trimethylation at H3K27 by influencing the phosphorylation of EZH2. To validate our hypothesis, we fist examined and compared the phosphorylation levels of EZH2 at Ser21 between genistein and TAM. After long-term TAM treatment, the phosphorylation of EZH2 at Ser21 was gradually increased (Fig. 3c). During long-term genistein exposure, the phosphorylation of EZH2 at Ser21 decreased first, and increased at 2 weeks and 3 weeks in T47D 
cells. Likewise, the phosphorylation of EZH2 also increased at 3 weeks in MCF-7 cells (Fig. 3b). These results suggest that phosphorylation of EZH2 at Ser21 may be responsible for the decrease of H3K27me3 during long-term genistein exposure. Unlike genistein, TAM had a stronger inhibitory effect on $\mathrm{H} 3 \mathrm{~K} 27$ trimethylation, due to enhancing phosphorylation of EZH2 and suppressing expression of EZH2 by antagonizing ER.

\section{ERK decreases the H3K27 trimethylation through phosphorylation of EZH2, contributing to HER2 expression and endocrine resistance}

We observed a similar trend in the changes of EZH2 phosphorylation and ERK1/2 phosphorylation after long-term genistein exposure. Accordingly, we evaluated whether phosphorylated ERK1/2 affects EZH2 phosphorylation, H3K27me3 levels. When MEK inhibitor U0126 treated T47D cells for 24h after 3 weeks with genistein, the results showed that inhibition of ERK1/2 phosphorylation downregulated genisteininduced EZH2 Ser21 phosphorylation, and up-regulated genistein-decreased H3K27me3 (Fig. 4a). When U0126 was combined with TAM, the results showed that inhibition of ERK1/2 phosphorylation also downregulated TAM-induced EZH2 phosphorylation at Ser21, up-regulated TAM-decreased H3K27me3 (Fig. 4b). Phosphorylation of EZH2 at Ser21 results in decreased EZH2 activity and H3K27me3 levels [34]. Other data suggest that low H3K27me3 levels are significantly associated with resistance to aromatase inhibitors in breast cancer patients [25]. To investigate whether H3K27me3 level was related to the expression of HER2 and the sensitivity to TAM, after exposure to $1 \mu \mathrm{M}$ genistein for 3 weeks, T47D cells were treated with EZH2 siRNA or GSK-J4, an H3K27 demethylase inhibitor. The results showed that GSKJ4 elevated the levels of H3K27me3, inhibited the expression of HER2 (Fig. 4c), and restored TAM sensitivity in T47D cells long exposed to genistein (Fig. 4d). However, EZH2 gene knockout lowered the levels of H3K27me3, promoted the expression of HER2 (Fig. 4e), and diminished the efficacy of TAM (Fig.4f). Increased phospho-EZH2 was not a result of increased total levels of EZH2, because phosphorylation of EZH2 remained unchanged in response to knocking down EZH2 expression (Fig. 4e). The above results suggested that activated ERK1/2 signaling phosphorylates EZH2 and reduces the trimethylation of H3K27. It has been reported that phosphorylation of EZH2 at Ser21 reduces the methylation for H3K27 [34]. Our findings revealed that reduction of H3K27me3 was involved in increasing expression of HER2 and reducing the sensitivity of the cells to TAM.

\section{Increased IL-6 and IL-8 induced by genistein is involved in HER2 elevation and endocrine resistance}

A decrease of H3K27me3 by EZH2 deficiency resulted in derepression of silenced IL- 6 and IL-8 in MCF-7 or another ER-positive T47D cells [35]. IL-6 is involved in TAM resistance through the downstream activation of multiple signaling pathways [36-38]. Previous study suggests a close link between IL-8 and traditional chemotherapy drug resistance [39]. IL- 6 and IL-8 may play critical roles in acquired endocrine resistance caused by genistein. Therefore, we analyzed expression of IL- 6 and IL- 8 in cells stimulated by prolong genistein. Both IL-6 mRNA and IL-8 mRNA significantly increased after 3 weeks of genistein exposure (Fig. 5a). After $24 \mathrm{~h}$ treatment, like $\mathrm{E}_{2}$, genistein inhibited IL-6 mRNA and IL-8 mRNA in MCF-7 cells (Fig. S4a), while only inhibited the expression of IL-6 mRNA in T47D cells (Fig. S4b). TAM, like 
prolong genistein, increased the expression of IL-6 and IL-8 mRNA (Fig. S4c and d). Our observations confirmed that knockdown of EZH2 gene elevated expression of IL-6 and IL-8 mRNA (Fig. 5b), and GSK$\mathrm{J} 4$ as an H3K27 demethylase inhibitor decreased expression of IL-6 and IL-8 mRNA (Fig. 5c). We analyzed the involvement of IL- 6 and IL-8 in HER2 expression and TAM resistance in breast cancer. Here we demonstrated that exogenous IL- 6 or IL-8 (24h treatment with recombinant IL- 6 or IL-8) elevated expression of HER2 in T47D cells (Fig. 5d). Results of further investigation indicated that IL-6 or IL-8 diminished the efficacy of to TAM (Fig. $5 \mathrm{e}$ and $\mathrm{f}$ ). Together, these results indicate that the elevation of HER2 promoted by IL- 6 or IL- 8 may be the cause of TAM resistance induced by genistein and EZH2 inactivation and H3K27me3 level reduction were involved in the enhanced expression of IL-6 and IL-8.

\section{Discussion}

Despite endocrine therapy has dramatically improved survival in ER-positive breast cancer patients, resistance to treatment is common, resulting in metastatic relapse that cannot be cured [40,41]. Much evidence has demonstrated that increased growth factor signaling, in particular the HER2 pathway contributes to endocrine therapy resistance [42]. HER2 gene expression can be down-regulated by $E_{2}$ in the MCF-7 breast cancer cell line [43] through direct transcriptional repression of the HER2 gene [44]. In the current study, genistein, like $E_{2}$, reduced the levels of HER2 and TAM increased the levels of HER2 after short-term treatment. Therefore, we believe that genistein may directly inhibit the transcription of HER2 gene through ER. After long-term exposure, genistein increased the expression of HER2, which is consistent with previous report in an athymic mice xenograft model [16]. Here we demonstrate that longterm exposure to genistein causes the development of acquired endocrine resistance in ER-positive breast cancer cells, in which HER2 may play an important role.

Many observations have confirmed the link between increased HER2 activity and phosphorylation of the downstream MAPK/ERK pathway [45]. TAM was shown to activate ERK in ER-positive MCF-7 and T47D cells but not in ER-negative MDA-MB-231 cells [46]. Unrestrained MAPK signaling phosphorylates Ser-118 in the ER [47,48], alters the ER association with corepressors of transcription [49], leading to loss of the inhibitory effect of TAM, which is a viable mechanism for MAPK to cause TAM resistance. Our previous study has shown that genistein induces activation of ERK1/2, starting at $3 \mathrm{~h}$ and peaking at $24 \mathrm{~h}$ [31]. In the present study, phosphorylation of ERK1/2 was high again from week 1 during long-term genistein exposure. Our study found that HER2 gene knockout resulted in decreased phosphorylation of ERK1/2. When inhibiting the phosphorylation of ERK1/2, the levels of HER2 protein were down-regulated. These data suggest that HER2 and ERK1/2 interact in a positive feedback regulation mode, which may be the reason for the unconstrained activation of ERK1/2. Meanwhile, HER2 expression is at a high level. Nonetheless, the data presented imply that MAPK may play a causal role in genistein-induced TAM resistance in ER-positive breast tumor cells.

Our further results suggest that the activated ERK1/2 signaling phosphorylated of EZH2 at Ser21 and down-regulated H3K27me3 level. EZH2 as a part of the polycomb repressive complex 2 (PRC2), possesses histone H3K27-specific methyltransferase activity [50]. Histone H3K27 methylation by EZH2 is 
an important mechanism of gene silencing [51]. Previous publications report that EZH2 is an estrogenregulated gene $[33,52,53]$. Here we found that genistein, as a phytoestrogen, up-regulated the levers of EZH2 and H3K27me3 in ER-positive breast cancer cells. However, after long-term genistein exposure, $\mathrm{EZH} 2$ protein levels have not changed significantly and the phosphorylation of EZH2 at Ser21 significantly increased. Phosphorylation of EZH2 at Ser21 dissociates EZH2 from chromatin resulting in decreased EZH2 activity and H3K27me3 levels [34], which is consistent with our results. We speculate that due to increased phosphorylation of EZH2, EZH2 protein levels did not increase as they did with short-term genistein exposure. Recent study has shown that EZH2 was evidently less enriched in TAMR cells [54]. Study has found that that low H3K27me3 level were significantly associated with aromatase inhibitor resistance [25]. In the current study, we demonstrated that decrease of H3K27me3 caused by EZH2 deficiency was associated with increased HER2 expression and genistein-induced TAM resistance. On the contrary, increase of H3K27me3 inhibited the expression of HER2 and restored TAM sensitivity in T47D cells long exposed to genistein.

$E_{2}$ is effective in suppressing TNFa induction of the IL-6 and IL-8 genes in MCF-7 cells [55]. Our findings indicated that genistein was equally effective in suppressing the expression of IL- 6 and IL-8 mRNA, possibly due to its estrogen-like activity. Long term anti-hormone therapy alters the function of ERa to create an inflammatory microenvironment in breast cancer [56]. However, we found that genistein upregulated the expression of IL- 6 and IL-8 after long-term exposure. Both IL- 6 and IL-8 increased the expression of HER2 and diminished the efficacy of to TAM. These data suggest that the up-regulation of inflammatory cytokine increased the levels of HER2, which may play a role in acquired endocrine resistance induced by long-term exposure of genistein. Unfortunately, the mechanism of IL-6 or IL-8 regulating HER2 expression has not been reported yet and further investigations are required to determine it.

In addition, we explored how inflammatory cytokines is elevated and which factors regulate them. Our data indicated that expression of IL-6 and IL-8 were significantly increased upon EZH2 silencing and significantly decreased upon H3K27 methylation enhancement. Our study disclosed EZH2 levels and activity were correlated negatively with inflammatory cytokines and that H3K27 methylation may account for the epigenetic repression, which is consistent with previous report [35]. For the first time, we have found that genistein induced TAM resistance via the EZH2/ H3K27me3/inflammatory cytokine /HER2 axis.

In summary, our work reveals a critical epigenetic program that determines HER2 expression as well as cell fate in response to TAM treatment (Fig. 6). In sensitive cells upon short-term exposure of genistein, the expression of HER2 is suppressed because of its estrogen-like function. However, long-term genistein exposure results in sustained activation of ERK $1 / 2$ and therefore induces a inactivation of epigenetic enzymes EZH2 by phosphorylation and decrease of H3K27me3 level, which causes high expression of inflammatory cytokines and HER2. Maintenance of HER2 protein at high level phosphorylates the downstream ERK1/2 and reprograms ERa-dependent transcriptional machinery, which renders acquired resistance phenotypes in breast cancer cells. TAM plays a similar role in this pathway. The difference is 
that TAM directly increases HER2 expression and inhibits EZH2 expression by antagonizing ER, even in the short term.

\section{Conclusions}

Taken together, our findings provide a compelling foundation for elucidating the endocrine resistance mechanism induced by genistein in breast cancer. The timing of exposure to phytoestrogens may be a key component in determining its effects. This study provides a comprehensive understanding of the health risks of dietary exposure to phytoestrogens in breast cancer patients. Breast cancer patients, especially those on TAM should be cautioned against the long-term use of soy supplements and purified products in order to achieve more lasting results.

\section{Abbreviations}

\begin{tabular}{|ll|}
\hline ER & estrogen receptor \\
\hline TAM & tamoxifen \\
\hline HER & human epidermal growth factor receptor \\
\hline GE & genistein \\
\hline EZH2 & enhancer of zeste homolog 2 \\
\hline H3K27me3 & trimethylation of histone H3 lysine 27 \\
\hline PRC2 & polycomb repressive complex 2 \\
\hline
\end{tabular}

\section{Declarations}

\section{Ethics approval and consent to participate}

Not applicable.

\section{Consent for publication}

All authors agree to the publication of the article.

\section{Availability of data and materials}

All data generated or analyzed during this study are included in this published article.

\section{Competing interests}

The authors declare that they have no competing interests.

\section{Funding}


This work was supported by National Natural Science Foundation of China $(81573183,81673205)$ and the Center for Global Health, School of Public Health, Nanjing Medical University. The project funded by the Priority Academic Program Development of Jiangsu Higher Education Institutions (PAPD).

\section{Authors' contributions}

$\mathrm{CH}$ and $\mathrm{QZ}$ are responsible for design, specific operation and data analysis of the experiment; $\mathrm{BY}, \mathrm{WX}, \mathrm{KJ}$, $\mathrm{KY}, \mathrm{MZ}$ are responsible for operation of the experiment; $\mathrm{ZL}$ is responsible for the writing of the article, experimental design and financial support. All authors read and approve the final manuscript.

\section{Acknowledgements}

Not applicable.

\section{Authors' information}

Chunyan Hu, Email: huchunyan@njmu.edu.cn.

Qian Zhou, Email: zhouqiannjum@163.com.

Bingmo Yang, Email: yangbingmonjmu@163.com.

Wei Xiao, xiaoweinjmu@163.com.

Kailin Jiao, Email: jklnjmu@163.com.

Keke Yang, Email: yangkekenjmu@163.com.

Ming Zhou, Email: mzhou78@163.com.

Zhong Li, Email: Iz-ny@njmu.edu.cn.

\section{References}

[1] EBCTCG. Effects of chemotherapy and hormonal therapy for early breast cancer on recurrence and 15year survival: an overview of the randomised trials. Lancet. 2005; 365:1687-717.

[2] Ellis AJ, Hendrick VM, Williams R, Komm BS. Selective estrogen receptor modulators in clinical practice: a safety overview. Expert Opin Drug Saf. 2015; 14(6):921-34.

[3] Rondón-Lagos M, Villegas VE, Rangel N, Sánchez MC, Zaphiropoulos PG. Tamoxifen resistance: emerging molecular targets. Int J Mol Sci. 2016; doi: 10.3390/ijms17081357.

[4] Massarweh S, Osborne CK, Creighton CJ, Qin L, Tsimelzon A, Huang S, Weiss H, Rimawi M, Schiff R. Tamoxifen resistance in breast tumors is driven by growth factor receptor signaling with repression of classic estrogen receptor genomic function. Cancer Research. 2008; 68(3):826-33. 
[5] Drury SC, Detre S, Leary A, Salter J, Reis-Filho J, Barbashina V, Marchio C, Lopez-Knowles E, Ghazoui Z, Habben $\mathrm{K}$, et al. Changes in breast cancer biomarkers in the IGF1R/PI3K pathway in recurrent breast cancer after tamoxifen treatment. Endocr Relat Cancer. 2011; 18(5):565-77.

[6] Schiff R, Massarweh SA, Shou J, Bharwani L, Arpino G, Rimawi M, Osborne CK. Advanced concepts in estrogen receptor biology and breast cancer endocrine resistance: implicated role of growth factor signaling and estrogen receptor coregulators. Cancer chemotherapy and pharmacology. 2005; 56 Suppl $1: 10-20$.

[7] Nicholson RI, Hutcheson IR, Britton D, Knowlden JM, Jones HE, Harper ME, Hiscox SE, Barrow D, Gee JM. Growth factor signalling networks in breast cancer and resistance to endocrine agents: new therapeutic strategies. The Journal of steroid biochemistry and molecular biology. 2005; 93(2-5):257-62.

[8] Gee JM, Robertson JF, Gutteridge E, Ellis IO, Pinder SE, Rubini M, Nicholson RI. Epidermal growth factor receptor/HER2/insulin-like growth factor receptor signalling and oestrogen receptor activity in clinical breast cancer. Endocr Relat Cancer. 2005; 12 Suppl 1:S99-S111.

[9] Dowsett M. Overexpression of HER-2 as a resistance mechanism to hormonal therapy for breast cancer. Endocrine-related cancer. 2001; 8(3):191-5.

[10] Arpino G, Wiechmann L, Osborne CK, Schiff R. Crosstalk between the estrogen receptor and the HER tyrosine kinase receptor family: molecular mechanism and clinical implications for endocrine therapy resistance. Endocr Rev. 2008; 29:217-33.

[11] Wang TT, Sathymoorthy N, Phang JM. Molecular effects genistein on estrogen receptor mediated pathways. Carcinogenesis. 1996; 17:271-5.

[12] Ju YH, Allred KF, Allred CD, Helferich WG. Genistein stimulates growth of human breast cancer cells in a novel, postmenopausal animal model, with low plasma estradiol concentrations. Carcinogenesis. 2006; 27: 1292-9.

[13] Schwartz JA, Liu G, Brooks SC. Genistein- mediated attenuation of tamoxifen-induced antag- onism from estrogen receptor-regulated genes. Biochem Biophys Res Commun. 1998; 253:38-43.

[14] Ju YH, Doerge DR, Allred KF, Allred CD, Helferich WG. Dietary genistein negates the inhibitory effect of tamoxifen on growth of estrogen-dependent human breast cancer (MCF-7) cells implanted in athymic mice. Cancer Res. 2002; 62: 2474-7.

[15] Liu B, Edgerton S, Yang X, Kim A, Ordonez-Ercan D, Mason T, Alvarez K, McKimmey C, Liu N, Thor A. Low-dose dietary phytoestrogen abrogates tamoxifen-associated mammary tumor prevention. Cancer Res. 2005; 65: 879-86.

[16] Andrade JE, Ju YH, Baker C, Doerge DR, Helferich WG. Long-term exposure to dietary sources of genistein induces estrogen-independence in the human breast cancer (MCF-7) xenograft model. Mol Nutr 
Food Res. 2015; 59:413-23.

[17] Sauvageau M, Sauvageau G. Polycomb group proteins: multi-faceted regulators of somatic stem cells and cancer. Cell Stem Cell. 2010; 7(3):299-313.

[18] Cao R, Wang L, Wang H, Xia L, Erdjument-Bromage H, Tempst P, Jones RS, Zhang Y. Role of histone H3 lysine 27 methylation in Polycomb-group silencing. Science. 2002; 298:1039-43.

[19] Kirmizis A, Bartley SM, Kuzmichev A, Margueron R, Reinberg D, Green R, Farnham PJ. Silencing of human polycomb target genes is associated with methylation of histone H3 Lys 27. Genes Dev. 2004; 18:1592-605.

[20] Kuzmichev A, Nishioka K, Erdjument-Bromage H, Tempst P, Reinberg D. Histone methyltransferase activity associated with a human multiprotein complex containing the Enhancer of Zeste protein. Genes Dev. 2002; 16:2893-905.

[21] Stone A, Valdes-Mora F, Clark SJ. Exploring and exploiting the aberrant DNA methylation profile of endocrine-resistant breast cancer. Epigenomics. 2013; 5(6):595-8.

[22] Nguyen VT, Barozzi I, Faronato M, Lombardo Y, Steel JH, Patel N, Darbre P, Castellano L, Győrffy B, Woodley $\mathrm{L}$, et al. Differential epigenetic reprogramming in response to specific endocrine therapies promotes cholesterol biosynthesis and cellular invasion. Nat Commun. 2015; doi:

10.1038/ncomms10044.

[23] Kleer CG, Cao Q, Varambally S, Shen R, Ota I, Tomlins SA, Ghosh D, Sewalt RG, Otte AP, Hayes DF, et al. EZH2 is a marker of aggressive breast cancer and promotes neoplastic transformation of breast epithelial cells. Proceedings of the National Academy of Sciences. 2003; 100:11606-11.

[24] Holm K, Grabau D, Lövgren K, Aradottir S, Gruvberger-Saal S, Howlin J, Saal LH, Ethier SP, Bendahl PO, Stål O, et al. Global H3K27 trimethylation and EZH2 abundance in breast tumor subtypes. Molecular Oncology. 2012; 6:494-506.

[25] Jansen MP, Knijnenburg T, Reijm EA, Simon I, Kerkhoven R, Droog M, Velds A, van Laere S, Dirix L, Alexi $X$, et al. Hallmarks of aromatase inhibitor drug resistance revealed by epigenetic profiling in breast cancer. Cancer Res. 2013; 73(22):6632-41.

[26] Greathouse KL, Bredfeldt T, Everitt JI, Lin K, Berry T, Kannan K, Mittelstadt ML, Ho SM, Walker CL. Environmental Estrogens Differentially Engage the Histone Methyltransferase EZH2 to Increase Risk of Uterine Tumorigenesis. Mol Cancer Res. 2012; 10(4):546-57.

[27] Johnston SR, Head J, Pancholi S, Detre S, Martin LA, Smith IE, Dowsett M. Integration of signal transduction inhibitors with endocrine therapy: an approach to overcoming hormone resistance in breast cancer. Clin Cancer Res. 2003; 9:524S-32S. 
[28] Wiseman H, Casey K, Bowey EA, Duffy R, Davies M, Rowland IR, Lloyd AS, Murray A, Thompson R, Clarke DB. Influence of $10 \mathrm{wk}$ of soy consumption on plasma concentrations and excretion of isoflavonoids and on gut microflora metabolism in healthy adults. Am J Clin Nutr. 2004; 80:692-9.

[29]. Fujimoto K, Tanaka M, Hirao Y, Nagata Y, Mori M, Miyanaga N, Akaza H, Kim WJ. Age-stratified serum levels of isoflavones and proportion of equol producers in Japanese and Korean healthy men. Prostate Cancer Prostatic Dis. 2008; 11:252-7.

[30] Gee JM, Robertson JF, Ellis IO \& Nicholson RI. Phosphorylation of ERK1/2 mitogen-activated protein kinase is associated with poor response to anti-hormonal therapy and decreased patient survival in clinical breast cancer. International Journal of Cancer. 2001; 95:247-54.

[31] Liu HQ, Du J, Hu CY, Qi H, Wang XR, Wang SL, Liu QZ, Li Z. Delayed activation of extracellular-signalregulated kinase $1 / 2$ is involved in genistein- and equol-induced cell proliferation and estrogen-receptoralpha-mediated transcription in MCF-7 breast cancer cells. J Nutr Biochem. 2010; 21, 390-6.

[32] Janes PW, Daly RJ, deFazio A., Sutherland R. L. Activation of the Ras signalling pathway in human breast cancer cells overexpressing erbB-2. Oncogene, 1994; 9: 3601-8.

[33] Bhan A, Hussain I, Ansari KI, Bobzean SA, Perrotti LI, Mandal SS. Histone methyltransferase EZH2 is transcriptionally in- duced by estradiol as well as estrogenic endocrine disruptors bisphenol-A and diethylstilbestrol. J Mol Biol. 2014; 426: 3426-41.

[34] Cha TL, Zhou BP, Xia W, Wu Y, Yang CC, Chen CT, Ping B, Otte AP, Hung MC. Akt-mediated phosphorylation of EZH2 suppresses methylation of lysine 27 in histone H3. Science. 2005; 310:306-10.

[35] Lee ST, Li Z, Wu Z, Aau M, Guan P, Karuturi RK, Liou YC, Yu Q. Context-specific regulation of NF-KB target gene expression by EZH2 in breast cancers. Mol Cell. 2011; 43(5):798-810.

[36] Shah N, Jin K, Cruz LA, Park S, Sadik H, Cho S, Goswami CP, Nakshatri H, Gupta R, Chang HY, et al. HOXB13 Mediates Tamoxifen Resistance and Invasiveness in Human Breast Cancer by Suppressing ERa and Inducing IL-6 ExpressionCancer Res. 2013; 73(17):5449-58. .

[37] Wang Y, Qu Y, Zhang XL, Xing J, Niu XL, Chen X, Li ZM. Autocrine production of interleukin- 6 confers ovarian cancer cells resistance to tamoxifen via ER isoforms and SRC-1. Mol Cell Endocrinol. 2014; 382(2):791-803.

[38] Kitajima S, Yoshida A, Kohno S, Li F, Suzuki S, Nagatani N, Nishimoto Y, Sasaki N, Muranaka H, Wan Y, et al. The RB-IL-6 Axis Controls Self-Renewal and Endocrine Therapy Resistance by Fine-Tuning Mitochondrial Activity. Oncogene. 2017; 36(36):5145-57.

[39] Shi Z, Yang WM, Chen LP, Yang DH, Zhou Q, Zhu J, Chen JJ, Huang RC, Chen ZS, Huang RP. Enhanced chemosensitization in multidrug-resistant human breast cancer cells by inhibition of IL- 6 and IL-8 production. Breast Cancer Res Treat. 2012; 135(3):737-47. 
[40] Raha P, Thomas S and Munster PN. Epigenetic modulation: A novel therapeutic target for overcoming hormonal therapy resistance. Epigenomics. 2011; 3: 451-70.

[41] Hurvitz SA and Pietras RJ. Rational management of endocrine resistance in breast cancer: A comprehensive review of estrogen receptor biology, treatment options, and future directions. Cancer. 2008; 113: 2385-97.

[42] Shou J, Massarweh S, Osborne C, Wakeling AE, Ali S, Weiss H, Schiff R. Mechanisms of tamoxifen resistance: increased estrogen receptor-HER2/neu cross-talk in ER/HER2-positive breast cancer. J Natl Cancer Inst. 2004; 96:926-35.

[43] Russell KS, Hung MC. Transcriptional repression of the neu protooncogene by estrogen stimulated estrogen receptor. Cancer Res. 1992; 52:6624-29.

[44] Bates NP, Hurst HC. An intron 1 enhancer element mediates oestrogen-induced suppression of ERBB2 expression. Oncogene. 1997; 15:473-81.

[45] Knowlden JM, Hutcheson IR, Jones HE, Madden T, Gee JM, Harper ME, Barrow D, Wakeling AE, Nicholson RI. Elevated levels of epidermal growth factor receptor/c-erbB2 heterodimers mediate an autocrine growth regulatory pathway in tamoxifen-resistant MCF-7 cells. Endocrinology. 2003; 144:103244.

[46] Zheng A, Kallio A and Härkönen P. Tamoxifen-induced rapid death of MCF-7 breast cancer cells is mediated via extracellularly signal-regulated kinase signaling and can be abrogated by estrogen. Endocrinology. 2007; 148: 2764-77.

[47] Kato S, Endoh H, Masuhiro Y, Kitamoto T, Uchiyama S, Sasaki H, Masushige S, Gotoh Y, Nishida E, Kawashima $\mathrm{H}$, et al. Activation of the estrogen receptor through phosphorylation by mitogen-activated protein kinase. Science (Washington DC). 1995; 270: 1491-4.

[48] Bunone G, Briand P A, Miksicek R J, Picard D. Activation of the unliganded estrogen receptor by EGF involves the MAP kinase pathway and direct phosphorylation. EMBO J. 1996; 15: 2174-83.

[49] Kurokawa H1, Lenferink AE, Simpson JF, Pisacane PI, Sliwkowski MX, Forbes JT, Arteaga CL.Inhibition of HER2/neu (erbB-2) and mitogen-activated protein kinases enhances tamoxifen action against HER2-overexpressing, tamoxifen-resistant breast cancer cells. Cancer Res. 2000; 60(20):5887-94.

[50] Guglielmelli P, Biamonte F, Score J, Hidalgo-Curtis C, Cervantes F, Maffioli M, Fanelli T, Ernst T, Winkelman N, Jones AV, et al. EZH2 mutational status predicts poor survival in myelofibrosis. Blood. 2011; 118:5227-34.

[51] Wang C, Liu Z, Woo C-W, Li Z, Wang L, Wei JS, Marquez VE, Bates SE, Jin Q, Khan J, et al. EZH2 mediates epigenetic silencing of neuroblastoma suppressor genes CASZ1, CLU, RUNX3, and NGFR. Cancer Res. 2012; 72:315-24. 
[52] Doherty LF, Bromer JG, Zhou Y, Aldad TS, Taylor HS. In utero exposure to diethylstilbestrol (DES) or bisphenol-A (BPA) increases EZH2 expression in the mammary gland: an epige- netic mechanism linking endocrine disruptors to breast can- cer. Horm Cancer. 2010; 1:146-55.

[53] Hu C, Liu Y, Teng M, Jiao K, Zhen J, Wu M, Li Z. Resveratrol inhibits the proliferation of estrogen receptor-positive breast cancer cells by suppressing EZH2 through the modulation of ERK1/2 signaling. Cell Biol Toxicol. 2019; 35(5):445-56.

[54] Kim CY, Oh JH, Lee JY, Kim MH. The LncRNA HOTAIRM1 Promotes Tamoxifen Resistance by Mediating HOXA1 Expression in ER+ Breast Cancer Cells. J Cancer. 2020; 11(12):3416-23.

[55] Nettles KW, Gil G, Nowak J, Metivier R, Sharma VB, Greene GL. Cbp is a dosage-dependent regulator of nuclear factor-kappab suppression by the estrogen receptor. Mol. Endocrinol. 2008; 22: 263-72.

[56] Baumgarten SC, Frasor J. Minireview. Inflammation: an instigator of more aggressive estrogen receptor (ER) positive breast cancers. Mol Endocrinol. 2012; 26:360-71.

\section{Figures}

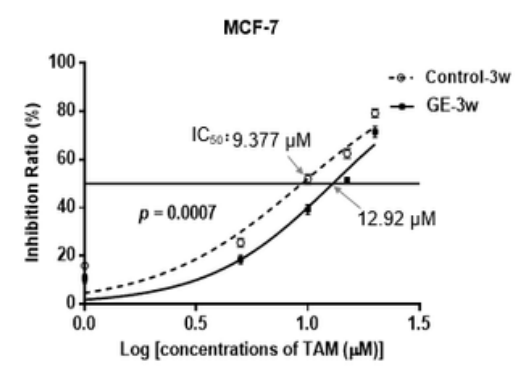

d

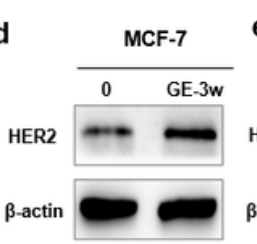

g

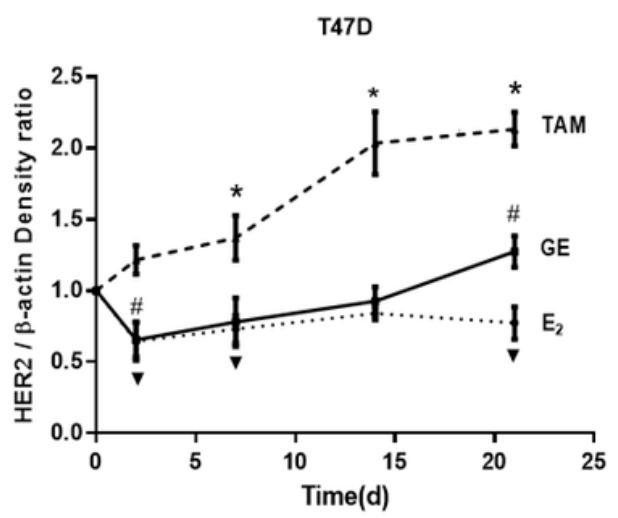

b

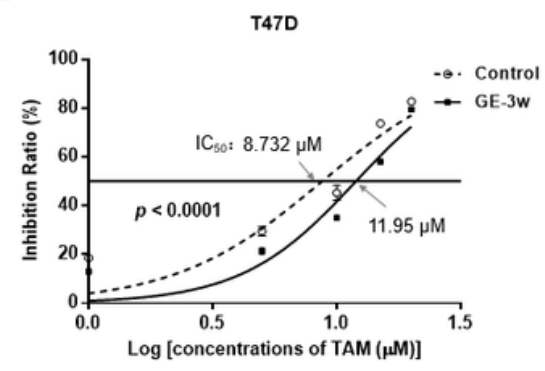

T47D c

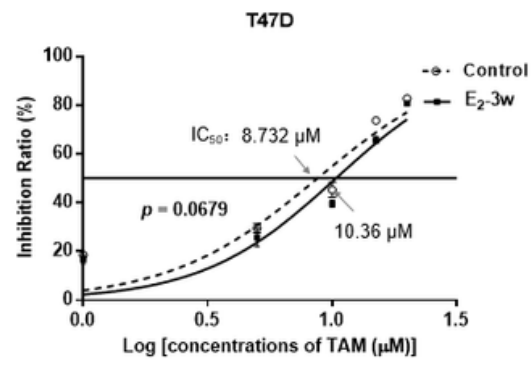

f

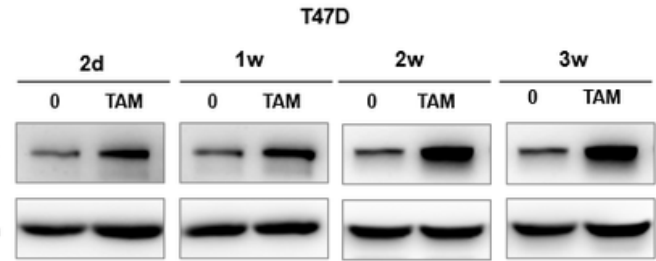

h

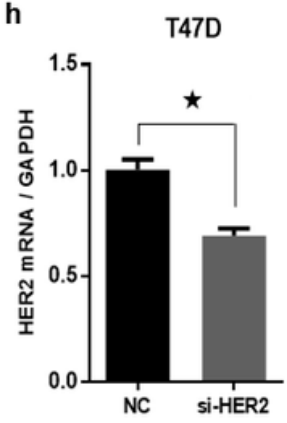

i

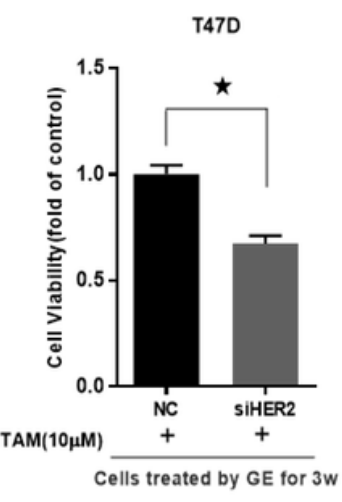




\section{Figure 1}

Elevated HER2 promotes to genistein - induced acquired endocrine therapy resistance (a) MCF-7 cells were treated by $1 \mu \mathrm{M}$ genistein for 3 weeks. (b) T47D cells were treated by $1 \mu \mathrm{M}$ genistein for 3 weeks. (c) T47D cells were treated by $1 \mathrm{nM}$ E2 for 3 weeks. After 3 weeks, the drug was removed, and after $24 \mathrm{~h}$, cells were treated with TAM for $48 \mathrm{~h}$. The cell viability was determined in quadruplicate, and the IC50s were calculated. (d) Western blot analysis was used to determine HER2 levels at 3 weeks after exposure to 1 $\mu \mathrm{M}$ genistein in MCF-7 cells. (e) Western blot analysis was used to determine HER2 levels at 2 days, 1 week, 2 weeks and 3 weeks after exposure to $1 \mu \mathrm{M}$ genistein or $1 \mathrm{nM} \mathrm{E2}$ in T47D cells. (f) Western blot analysis was used to determine HER2 levels at 2 days, 1 week, 2 weeks and 3 weeks after treatment with $1 \mu \mathrm{M}$ TAM in T47D cells. (g) Expression of HER2 was normalized to the $\beta$-actin control in each lane in triple. *\# $\boldsymbol{\nabla}$ p $<0.05$ vs. control cells. (h) The mRNA levels of HER2 were assessed by PCR and the protein levels of HER2 were measured by western blot analysis in T47D cells transfected with HER2 siRNA for 6h. (i) T47D cells were treated by $1 \mu \mathrm{M}$ genistein for 3 weeks. After 3 weeks, genistein was removed, and cells were transfected with NC or HER2 siRNA for $6 \mathrm{~h}$ respectively, and then treated with $10 \mu \mathrm{M}$ TAM for $48 \mathrm{~h}$. Data of the mRNA are expressed as the mean $\pm \operatorname{SD}(n=3)$. control group. Data of the cell viability are expressed as the mean $\pm S D(n=4), \otimes p<0.05$ vs. NC group.

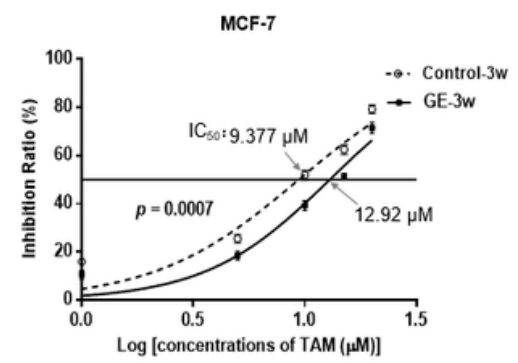

d

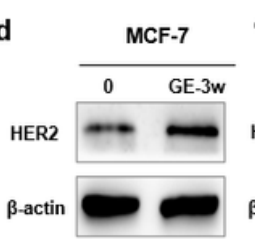

g

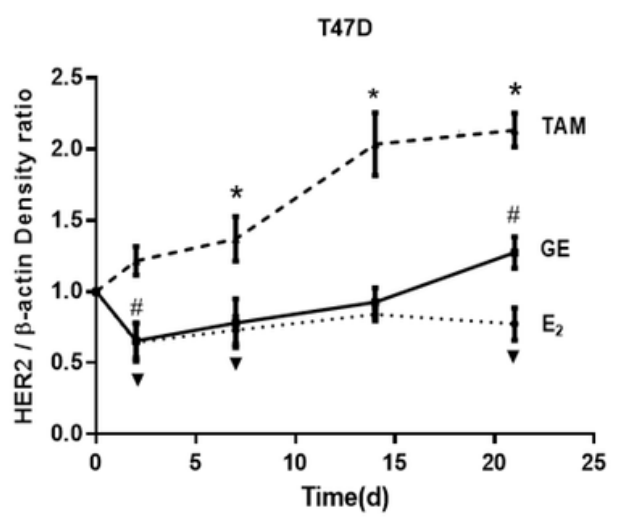

b

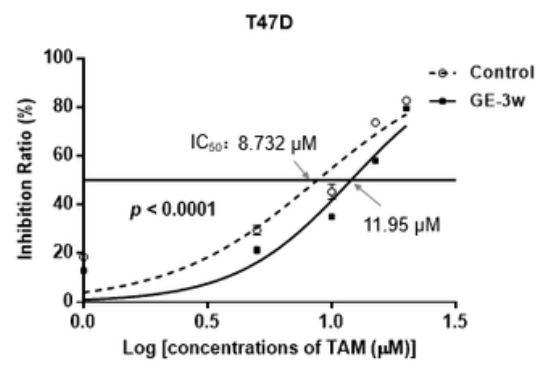

T47D

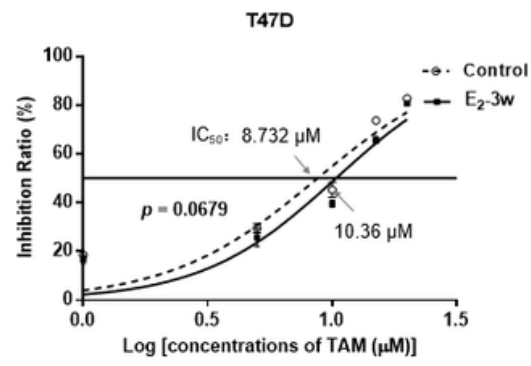

f

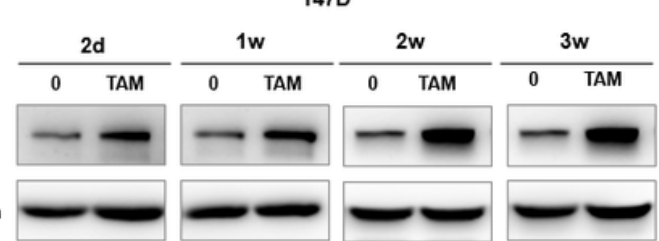

Figure 1

h

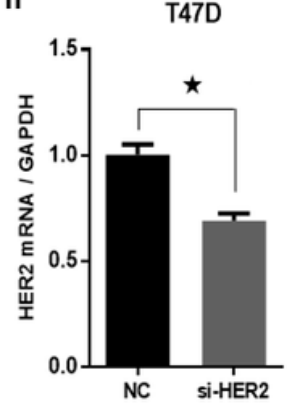

i

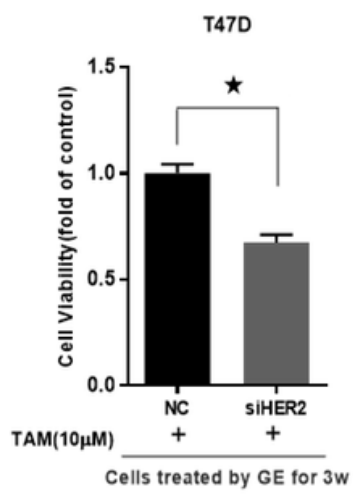


Elevated HER2 promotes to genistein - induced acquired endocrine therapy resistance (a) MCF-7 cells were treated by $1 \mu \mathrm{M}$ genistein for 3 weeks. (b) T47D cells were treated by $1 \mu \mathrm{M}$ genistein for 3 weeks. (c) T47D cells were treated by $1 \mathrm{nM}$ E2 for 3 weeks. After 3 weeks, the drug was removed, and after $24 \mathrm{~h}$, cells were treated with TAM for $48 \mathrm{~h}$. The cell viability was determined in quadruplicate, and the IC50s were calculated. (d) Western blot analysis was used to determine HER2 levels at 3 weeks after exposure to 1 $\mu \mathrm{M}$ genistein in MCF-7 cells. (e) Western blot analysis was used to determine HER2 levels at 2 days, 1 week, 2 weeks and 3 weeks after exposure to $1 \mu \mathrm{M}$ genistein or $1 \mathrm{nM} \mathrm{E2}$ in T47D cells. (f) Western blot analysis was used to determine HER2 levels at 2 days, 1 week, 2 weeks and 3 weeks after treatment with $1 \mu \mathrm{M}$ TAM in T47D cells. (g) Expression of HER2 was normalized to the $\beta$-actin control in each lane in triple. ${ }^{*} \# \boldsymbol{\nabla} p<0.05$ vs. control cells. (h) The mRNA levels of HER2 were assessed by PCR and the protein levels of HER2 were measured by western blot analysis in T47D cells transfected with HER2 siRNA for 6h. (i) T47D cells were treated by $1 \mu \mathrm{M}$ genistein for 3 weeks. After 3 weeks, genistein was removed, and cells were transfected with NC or HER2 siRNA for $6 \mathrm{~h}$ respectively, and then treated with $10 \mu \mathrm{M}$ TAM for $48 \mathrm{~h}$. Data of the mRNA are expressed as the mean $\pm S D(n=3)$. control group. Data of the cell viability are expressed as the mean $\pm S D(n=4), \nabla p<0.05$ vs. NC group.

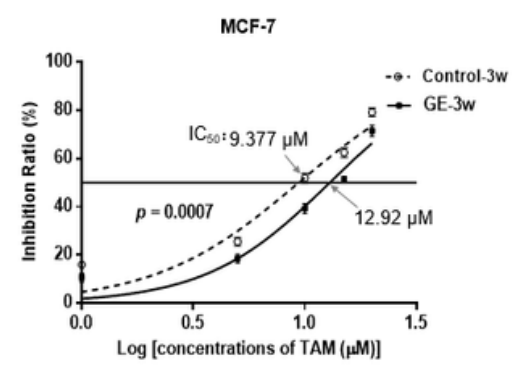

d

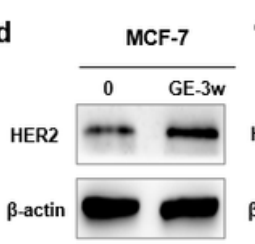

g

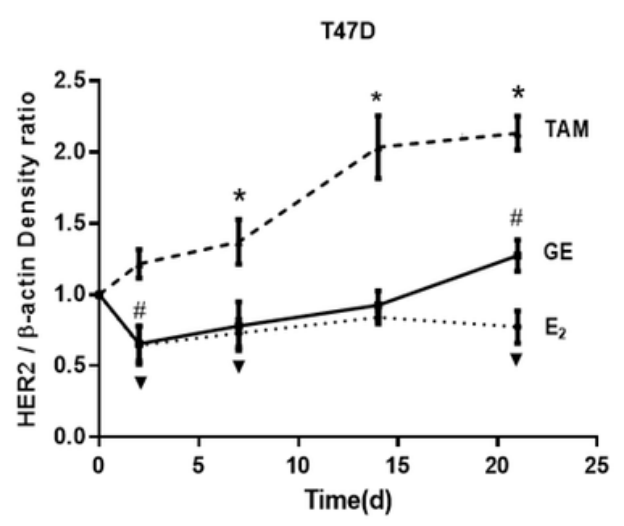

b

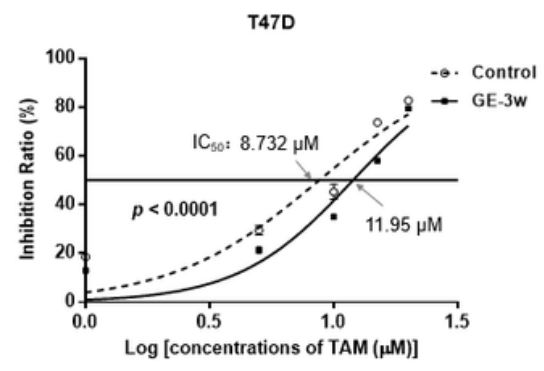

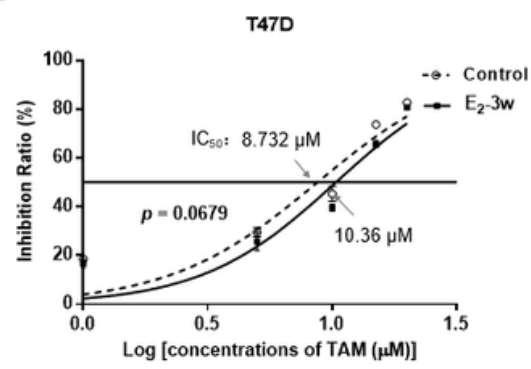

f

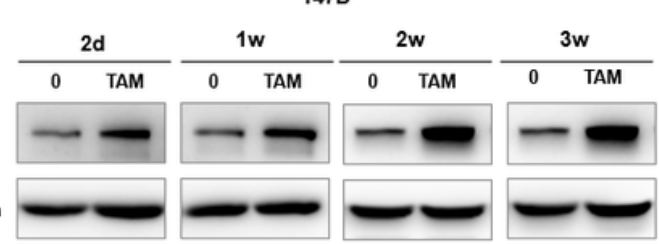

T47D

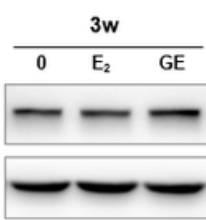

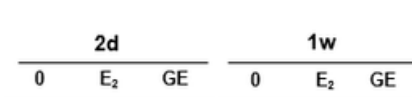

\begin{tabular}{lll}
\multicolumn{2}{c}{$2 \mathrm{w}$} & \\
\hline 0 & $\mathrm{E}_{2}$ & $\mathrm{GE}$
\end{tabular} $\mathbf{h}$

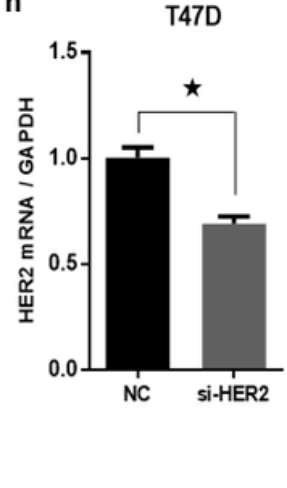

i

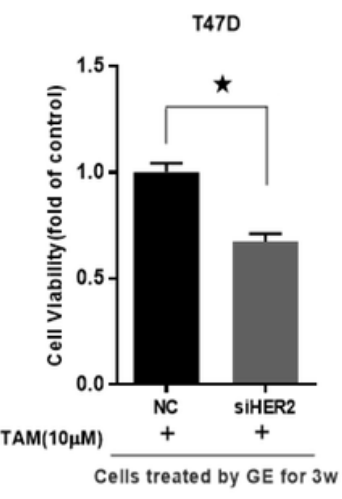

Figure 1 
Elevated HER2 promotes to genistein - induced acquired endocrine therapy resistance (a) MCF-7 cells were treated by $1 \mu \mathrm{M}$ genistein for 3 weeks. (b) T47D cells were treated by $1 \mu \mathrm{M}$ genistein for 3 weeks. (c) T47D cells were treated by $1 \mathrm{nM}$ E2 for 3 weeks. After 3 weeks, the drug was removed, and after $24 \mathrm{~h}$, cells were treated with TAM for $48 \mathrm{~h}$. The cell viability was determined in quadruplicate, and the IC50s were calculated. (d) Western blot analysis was used to determine HER2 levels at 3 weeks after exposure to 1 $\mu \mathrm{M}$ genistein in MCF-7 cells. (e) Western blot analysis was used to determine HER2 levels at 2 days, 1 week, 2 weeks and 3 weeks after exposure to $1 \mu \mathrm{M}$ genistein or $1 \mathrm{nM}$ E2 in T47D cells. (f) Western blot analysis was used to determine HER2 levels at 2 days, 1 week, 2 weeks and 3 weeks after treatment with $1 \mu \mathrm{M}$ TAM in T47D cells. (g) Expression of HER2 was normalized to the $\beta$-actin control in each lane in triple. *\# $\boldsymbol{\nabla} p<0.05$ vs. control cells. (h) The mRNA levels of HER2 were assessed by PCR and the protein levels of HER2 were measured by western blot analysis in T47D cells transfected with HER2 siRNA for 6h. (i) T47D cells were treated by $1 \mu \mathrm{M}$ genistein for 3 weeks. After 3 weeks, genistein was removed, and cells were transfected with NC or HER2 siRNA for $6 \mathrm{~h}$ respectively, and then treated with $10 \mu \mathrm{M}$ TAM for $48 \mathrm{~h}$. Data of the mRNA are expressed as the mean $\pm S D(n=3)$. control group. Data of the cell viability are expressed as the mean $\pm S D(n=4), \otimes p<0.05$ vs. NC group.

a

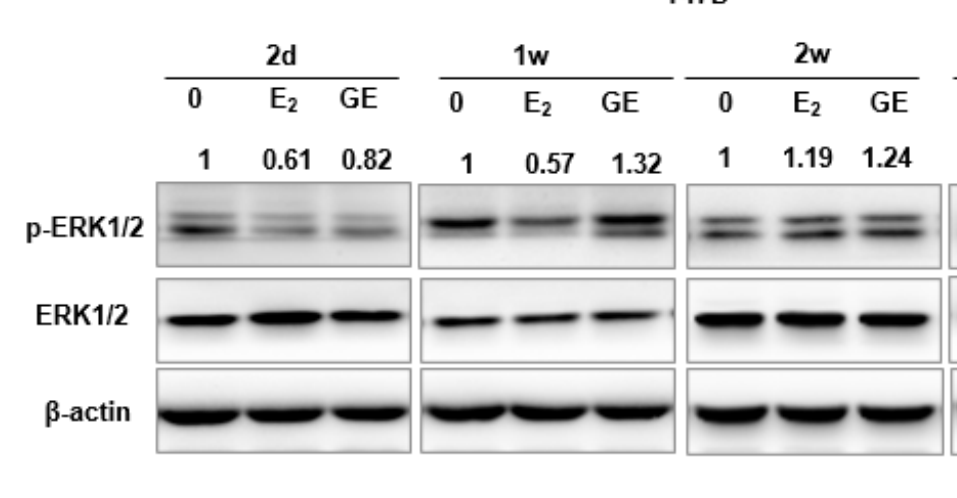

c

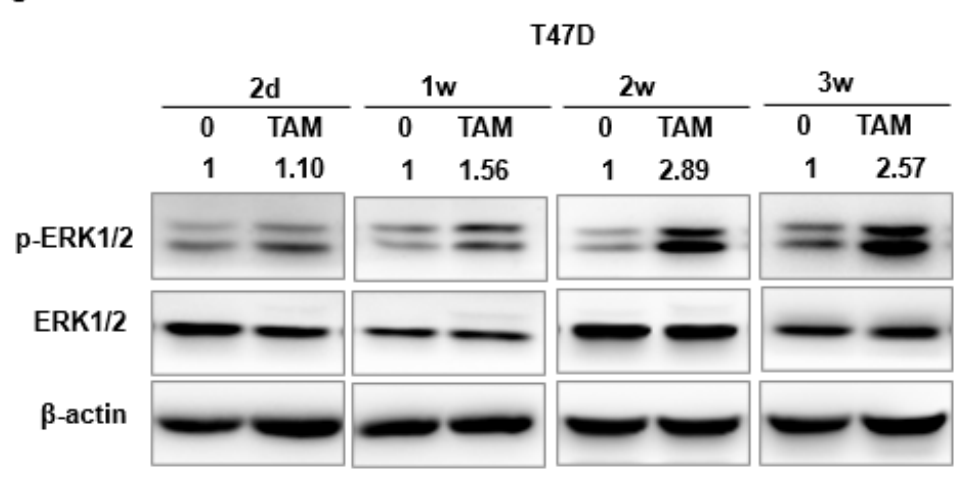

b

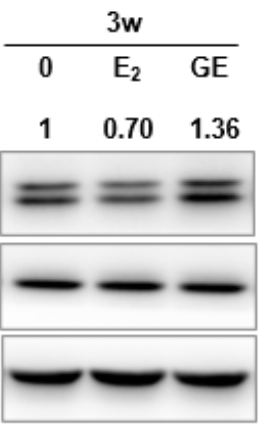

d

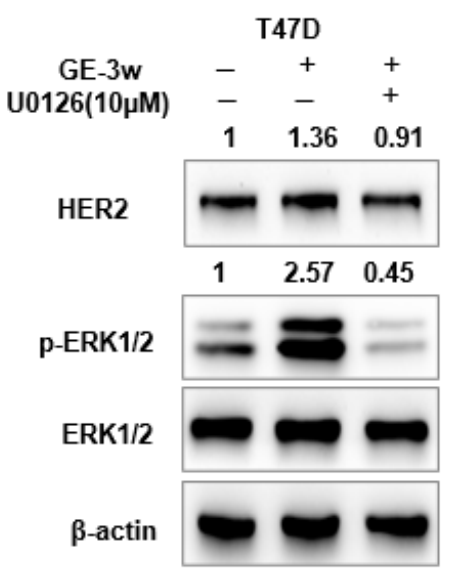

MCF-7
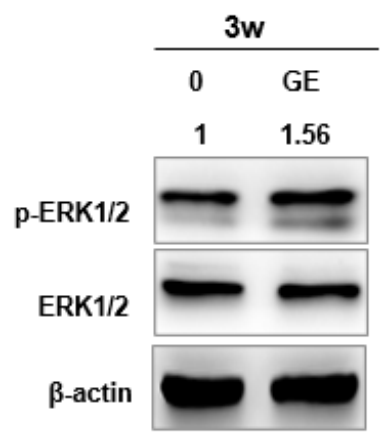

e

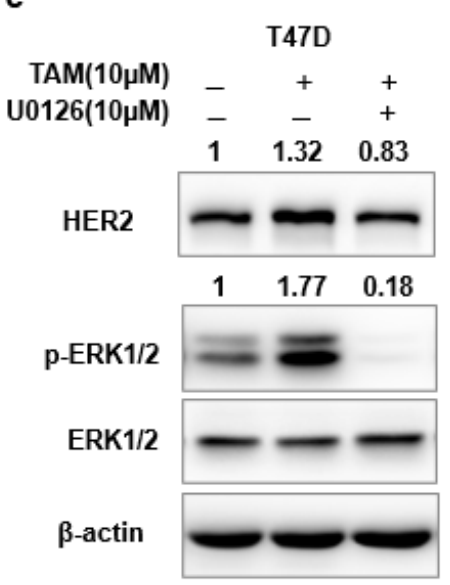

\section{Figure 2}

ERK1/2 signal activation caused by long-term exposure to genistein is associated with HER2 elevation (a) Western blot analysis was used to determine phospho-ERK1/2 and ERK1/2 levels at 2 days, 1 week, 2 weeks and 3 weeks after exposure to $1 \mu \mathrm{M}$ genistein or $1 \mathrm{nM}$ E2 in T47D cells. (b) Western blot analysis 
was used to determine phospho-ERK1/2 and ERK1/2 levels at 3 weeks after exposure to $1 \mu \mathrm{M}$ genistein in MCF-7 cells. (c) Western blot analysis was used to determine phospho-ERK1/2 and ERK1/2 levels at 2 days, 1 week, 2 weeks and 3 weeks after treatment with $1 \mu \mathrm{M}$ TAM in T47D cells. (d) T47D cells were exposed by $1 \mu \mathrm{M}$ genistein for 3 weeks. After 3 weeks, genistein was removed, and cells were treated with $10 \mu \mathrm{M}$ U0126 for 24h. The protein levels of HER2, phospho-ERK1/2 and ERK1/2 were determined by Western-blot analysis. (e) The protein levels of HER2, phospho-ERK1/2 and ERK1/2 were determined by Western-blot analysis in T47D cells treated with $10 \mu \mathrm{M}$ TAM alone for $24 \mathrm{~h}$ or in combination with $10 \mu \mathrm{M}$ U0126 for $24 \mathrm{~h}$.

a

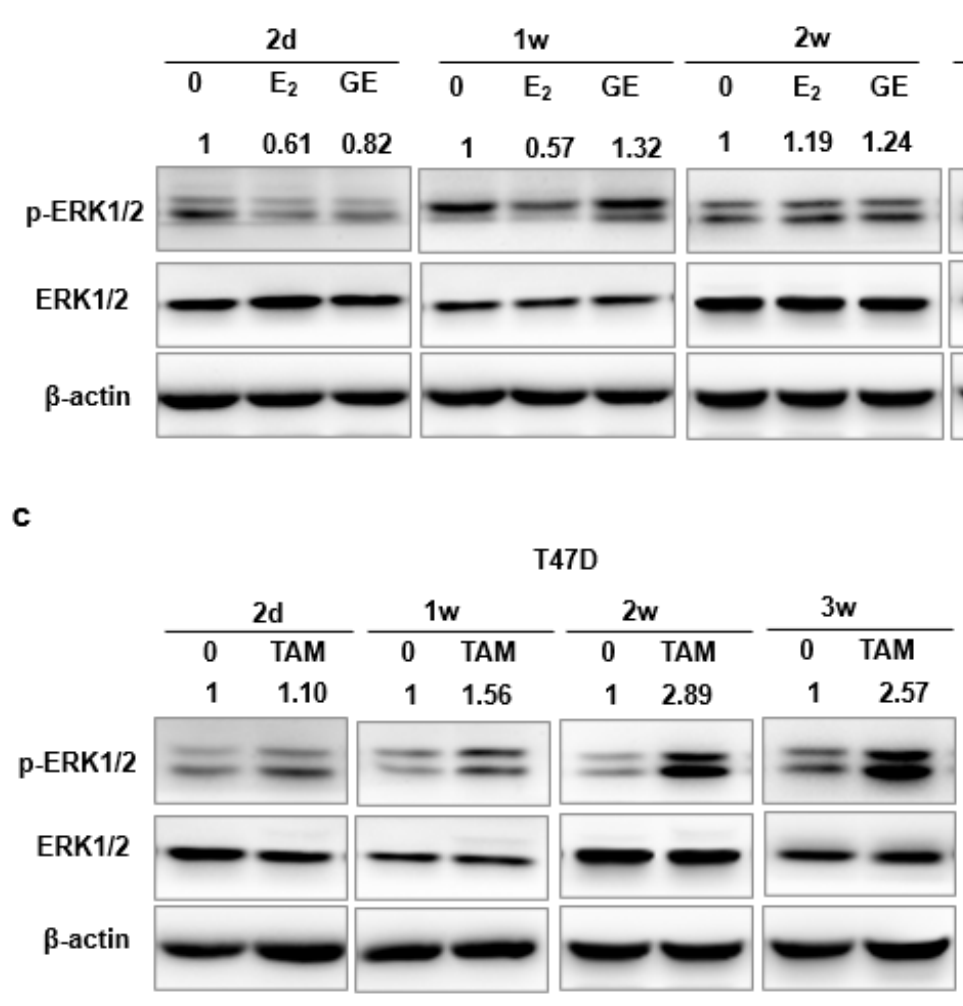

b

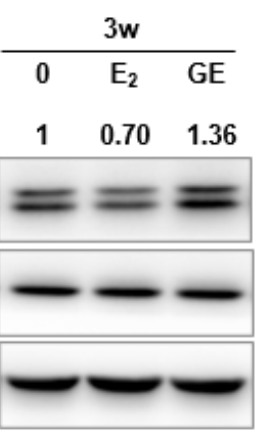

d

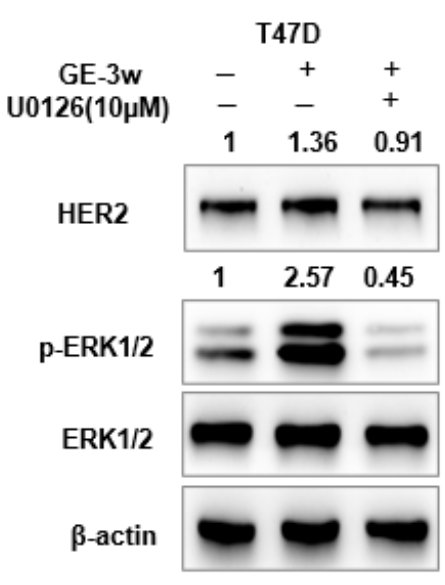

MCF-7
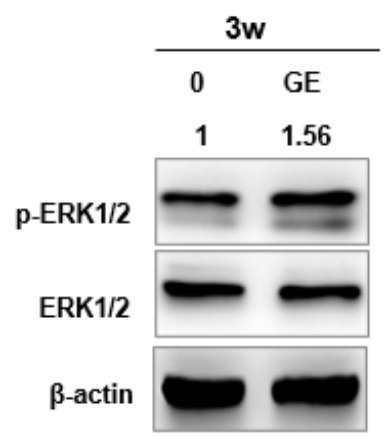

e

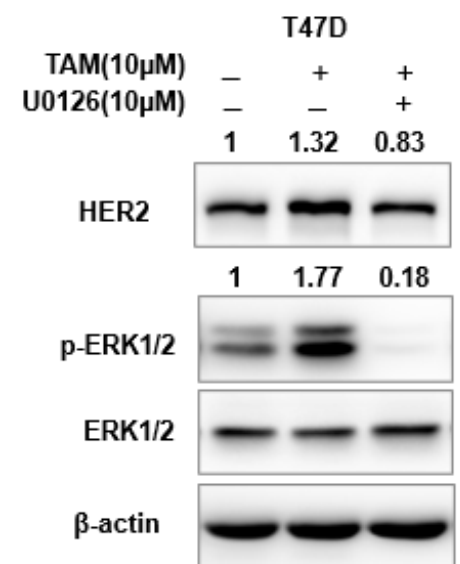

Figure 2

ERK1/2 signal activation caused by long-term exposure to genistein is associated with HER2 elevation (a) Western blot analysis was used to determine phospho-ERK1/2 and ERK1/2 levels at 2 days, 1 week, 2 weeks and 3 weeks after exposure to $1 \mu \mathrm{M}$ genistein or $1 \mathrm{nM}$ E2 in T47D cells. (b) Western blot analysis was used to determine phospho-ERK1/2 and ERK1/2 levels at 3 weeks after exposure to $1 \mu \mathrm{M}$ genistein in MCF-7 cells. (c) Western blot analysis was used to determine phospho-ERK1/2 and ERK1/2 levels at 2 days, 1 week, 2 weeks and 3 weeks after treatment with $1 \mu$ M TAM in T47D cells. (d) T47D cells were exposed by $1 \mu \mathrm{M}$ genistein for 3 weeks. After 3 weeks, genistein was removed, and cells were treated with $10 \mu \mathrm{M} \cup 0126$ for $24 \mathrm{~h}$. The protein levels of HER2, phospho-ERK1/2 and ERK1/2 were determined by Western-blot analysis. (e) The protein levels of HER2, phospho-ERK1/2 and ERK1/2 were determined by 
Western-blot analysis in T47D cells treated with $10 \mu \mathrm{M}$ TAM alone for $24 \mathrm{~h}$ or in combination with $10 \mu \mathrm{M}$ U0126 for $24 \mathrm{~h}$.

a

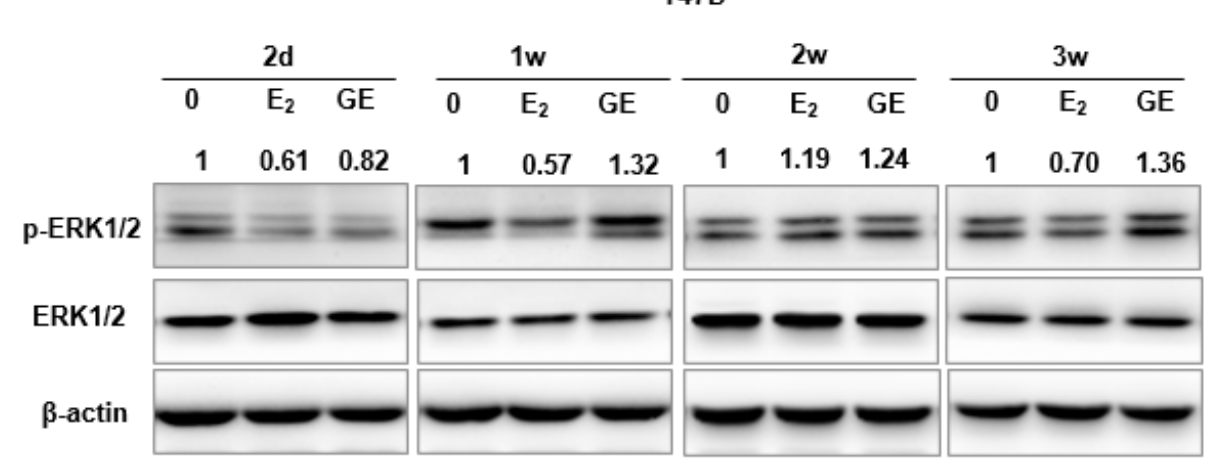

b

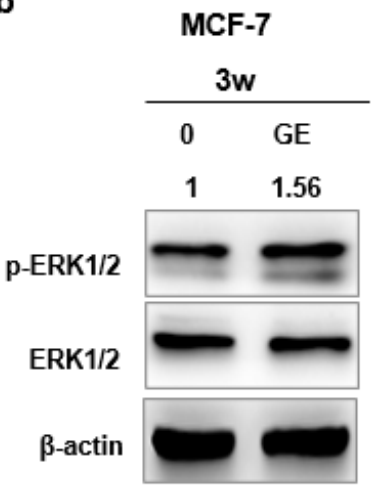

c

T47D

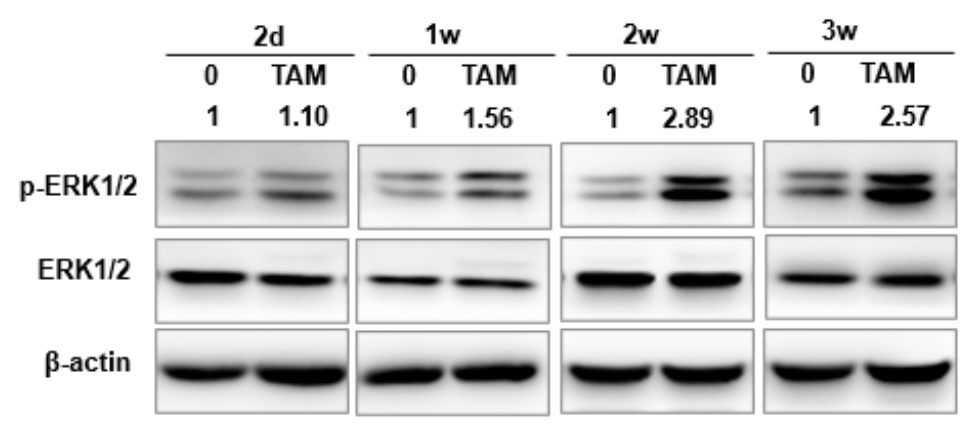

d

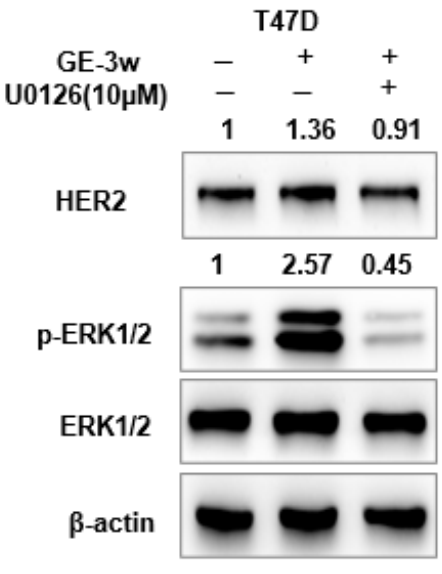

e

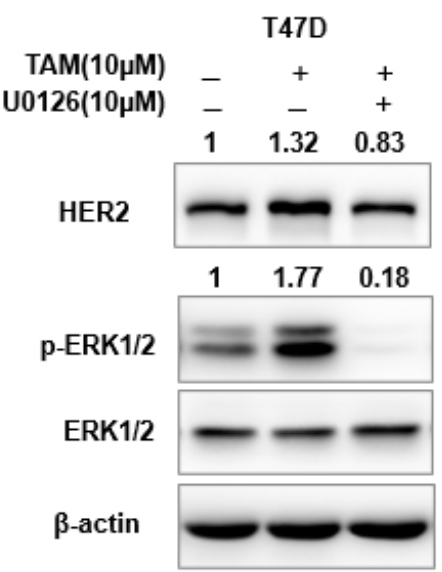

Figure 2

ERK1/2 signal activation caused by long-term exposure to genistein is associated with HER2 elevation (a) Western blot analysis was used to determine phospho-ERK1/2 and ERK1/2 levels at 2 days, 1 week, 2 weeks and 3 weeks after exposure to $1 \mu \mathrm{M}$ genistein or $1 \mathrm{nM}$ E2 in T47D cells. (b) Western blot analysis was used to determine phospho-ERK1/2 and ERK1/2 levels at 3 weeks after exposure to $1 \mu \mathrm{M}$ genistein in MCF-7 cells. (c) Western blot analysis was used to determine phospho-ERK $1 / 2$ and ERK $1 / 2$ levels at 2 days, 1 week, 2 weeks and 3 weeks after treatment with $1 \mu$ M TAM in T47D cells. (d) T47D cells were exposed by $1 \mu \mathrm{M}$ genistein for 3 weeks. After 3 weeks, genistein was removed, and cells were treated with $10 \mu \mathrm{M}$ U0126 for 24h. The protein levels of HER2, phospho-ERK1/2 and ERK1/2 were determined by Western-blot analysis. (e) The protein levels of HER2, phospho-ERK1/2 and ERK1/2 were determined by Western-blot analysis in T47D cells treated with $10 \mu \mathrm{M}$ TAM alone for $24 \mathrm{~h}$ or in combination with $10 \mu \mathrm{M}$ U0126 for $24 \mathrm{~h}$. 
a

T47D

C

MCF-7

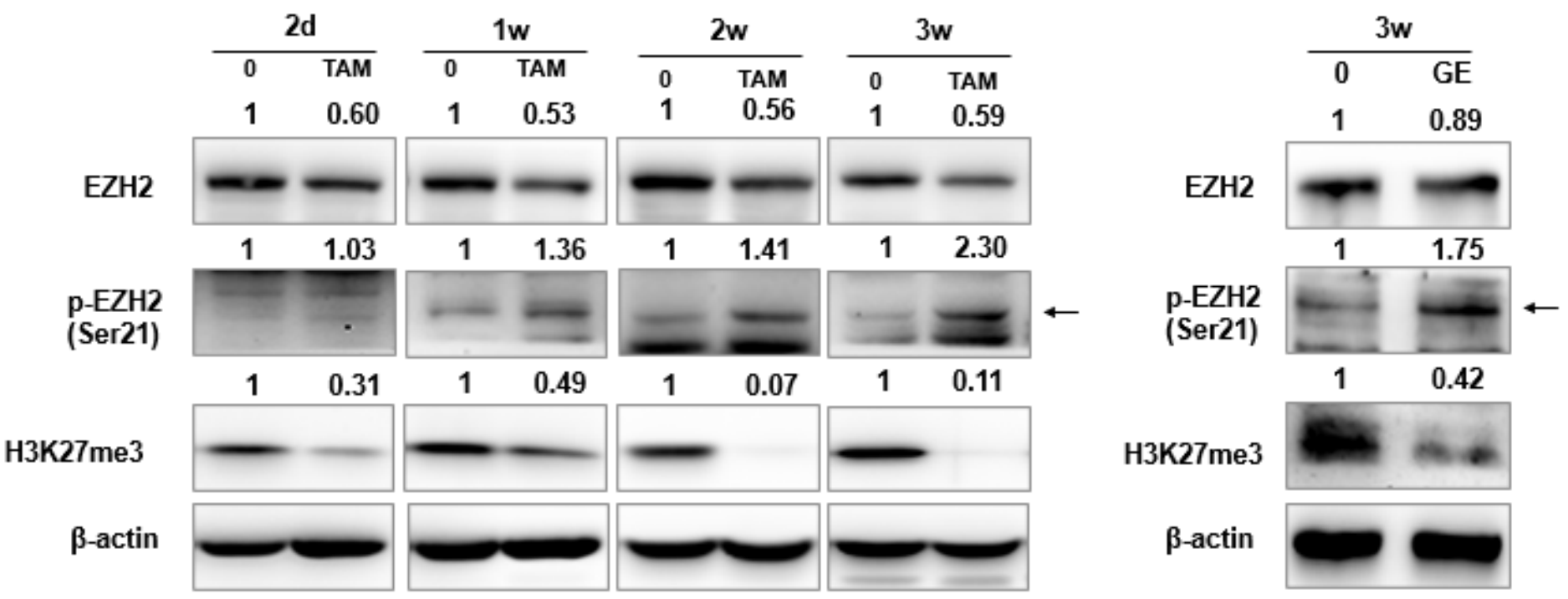

b

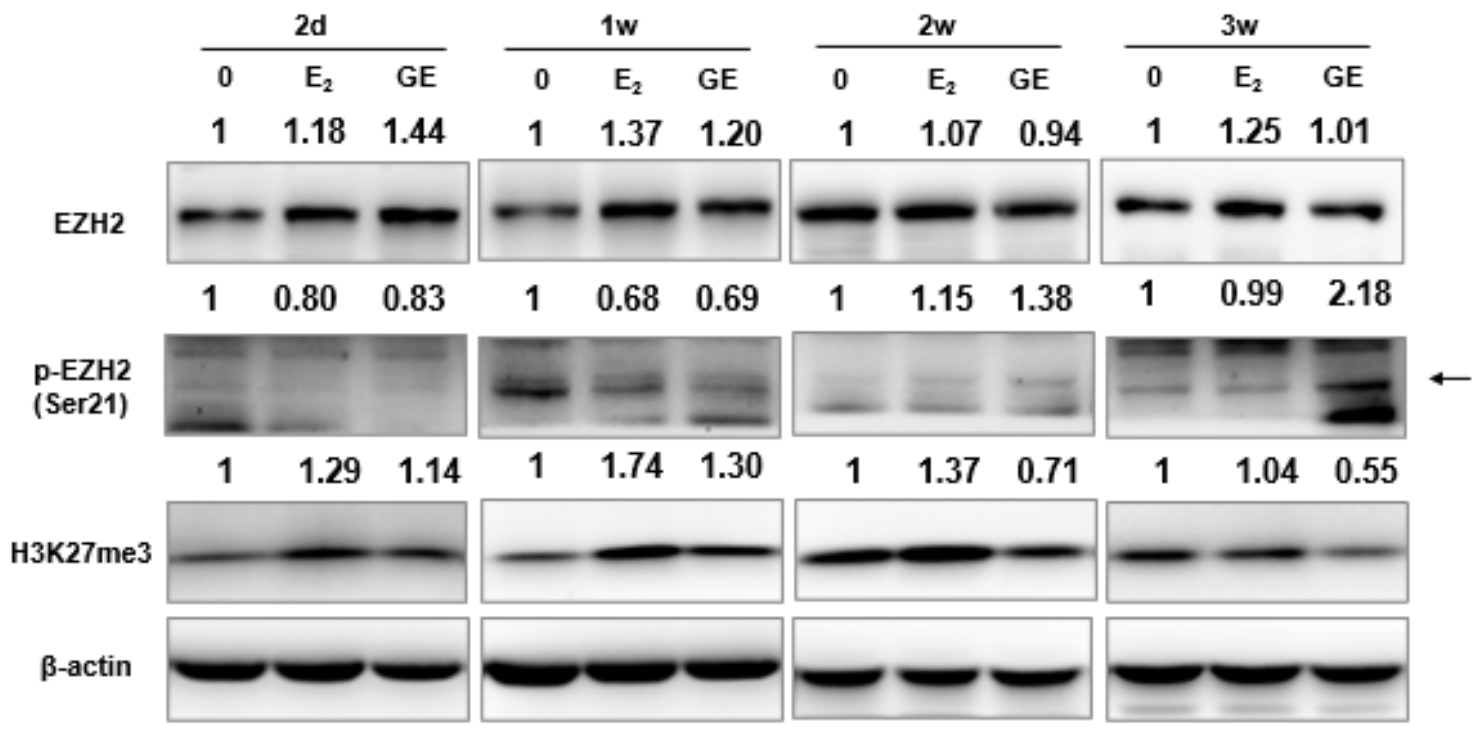

Figure 3

EZH2 phosphorylation at Ser21 increases and H3K27me3 levels reduce during long-term genistein exposure (a) Western blot analysis was used to determine phospho-EZH2(Ser21), EZH2 and H3K27me3 levels at 2 days, 1 week, 2 weeks and 3 weeks after treatment with $1 \mu$ M TAM in T47D cells. (b) Western blot analysis was used to determine phospho-EZH2(Ser21), EZH2 and H3K27me3 levels at 2 days, 1 week, 2 weeks and 3 weeks after exposure to $1 \mu \mathrm{M}$ genistein or $1 \mathrm{nM}$ E2 in T47D cells. (c) Western blot analysis was used to determine phospho-EZH2(Ser21), EZH2 and H3K27me3 levels at 3 weeks after exposure to $1 \mu \mathrm{M}$ genistein in MCF-7 cells. 
a

T47D

C

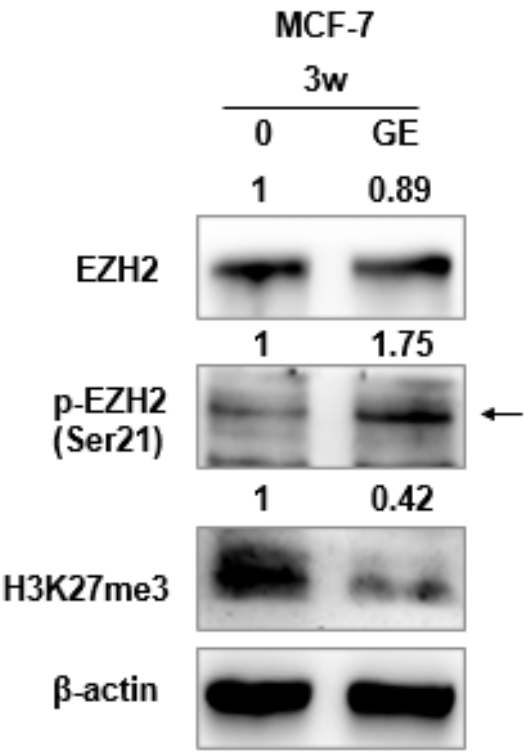

b
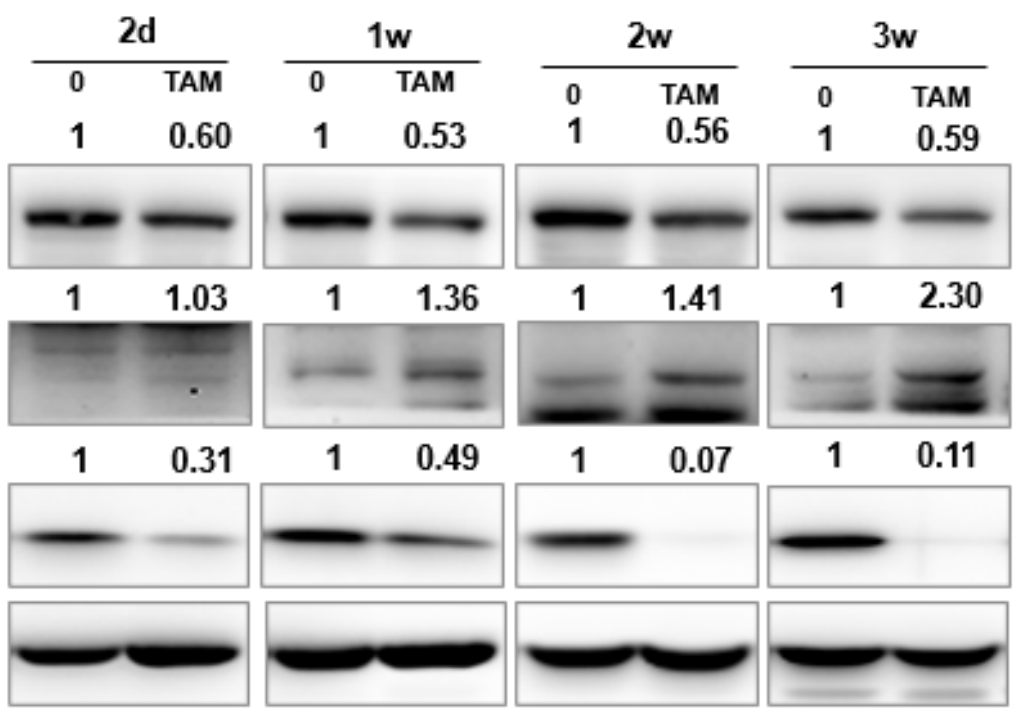

p-EZH2
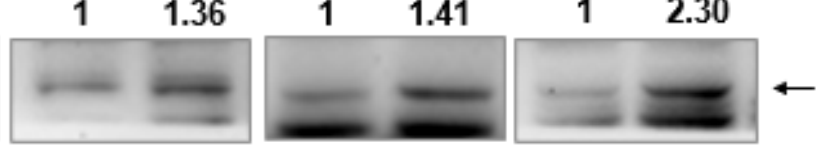

H3K27me3

$\beta$-actin
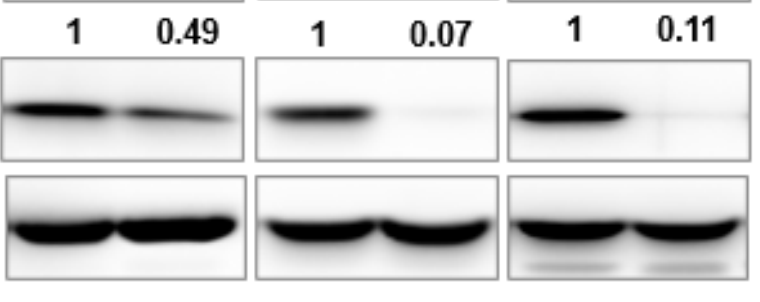

T47D

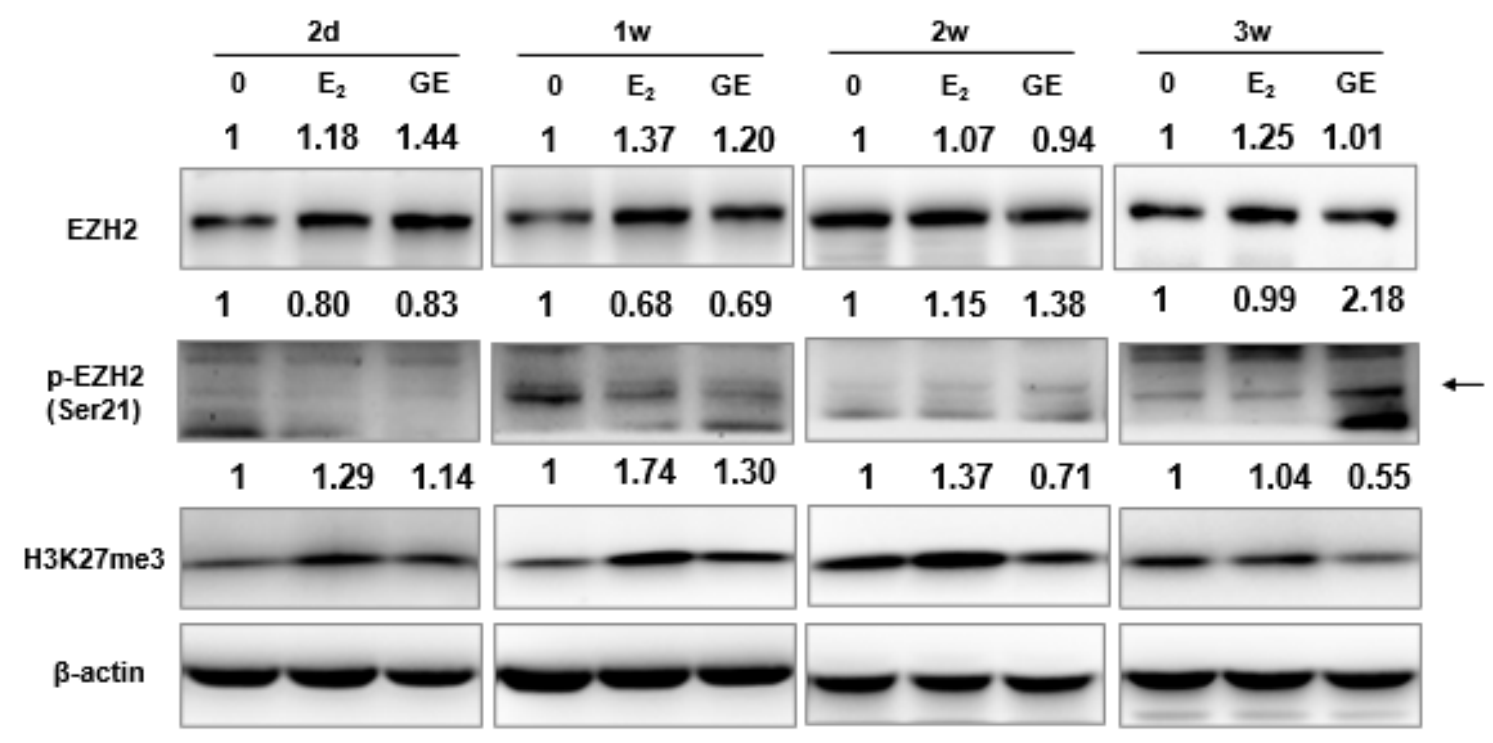

\section{Figure 3}

EZH2 phosphorylation at Ser21 increases and H3K27me3 levels reduce during long-term genistein exposure (a) Western blot analysis was used to determine phospho-EZH2(Ser21), EZH2 and H3K27me3 levels at 2 days, 1 week, 2 weeks and 3 weeks after treatment with $1 \mu$ M TAM in T47D cells. (b) Western blot analysis was used to determine phospho-EZH2(Ser21), EZH2 and H3K27me3 levels at 2 days, 1 week, 2 weeks and 3 weeks after exposure to $1 \mu \mathrm{M}$ genistein or $1 \mathrm{nM}$ E2 in T47D cells. (c) Western blot analysis was used to determine phospho-EZH2(Ser21), EZH2 and H3K27me3 levels at 3 weeks after exposure to $1 \mu \mathrm{M}$ genistein in MCF-7 cells. 
a

T47D

C

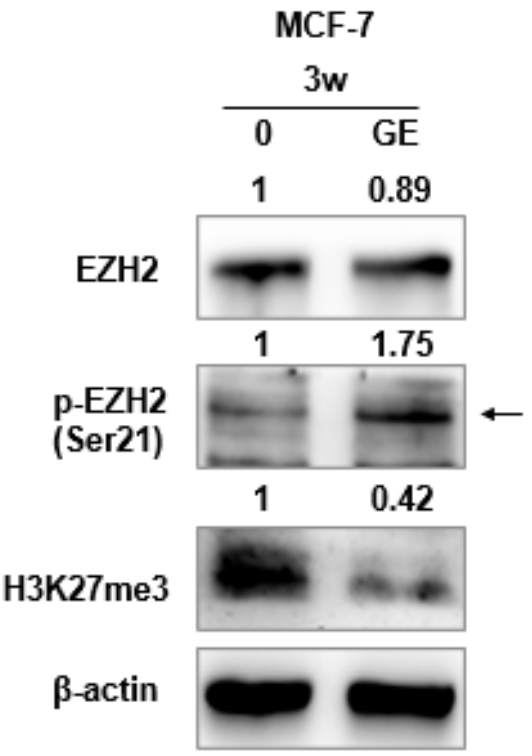

b
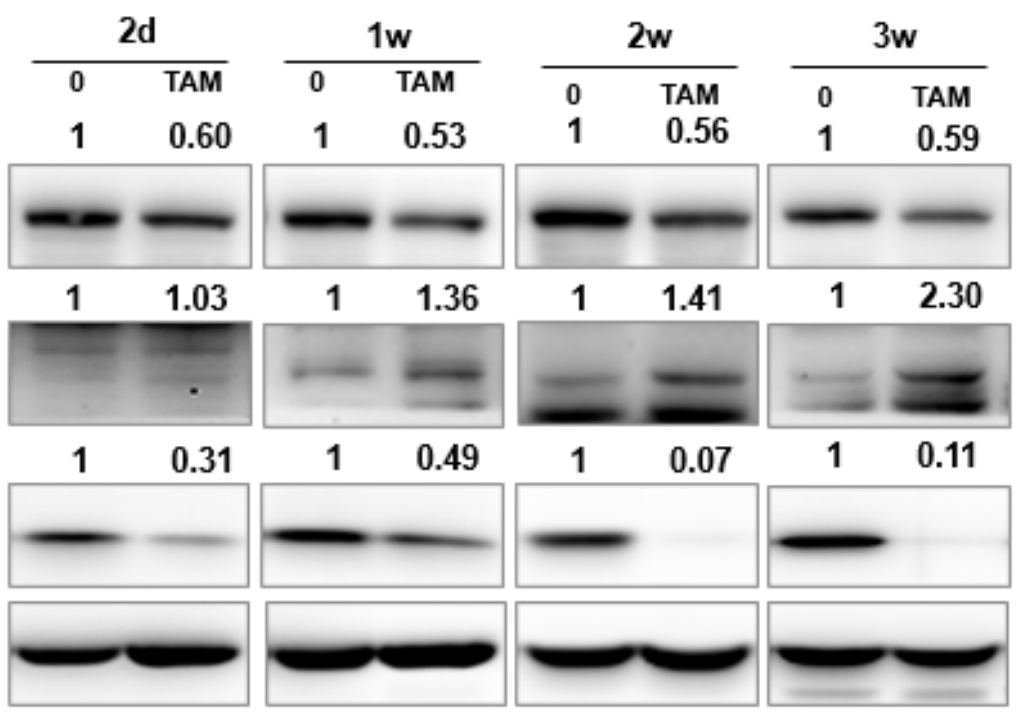

p-EZH2
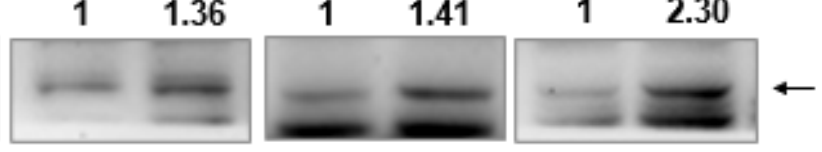

H3K27me3

$\beta$-actin
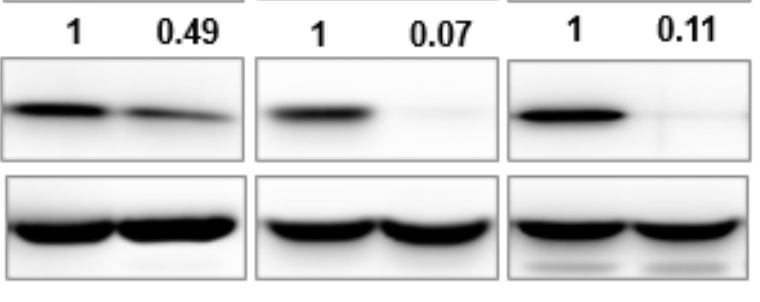

T47D

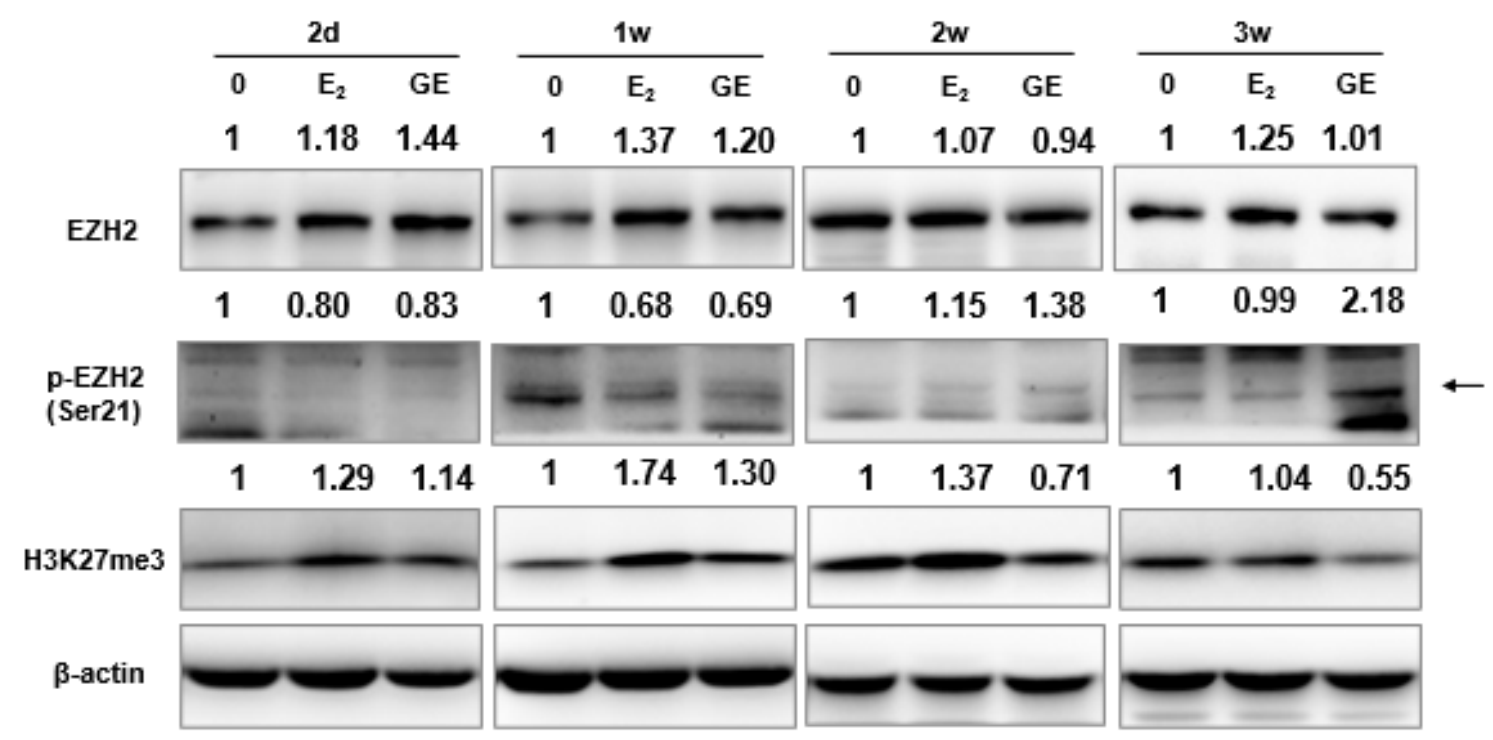

\section{Figure 3}

EZH2 phosphorylation at Ser21 increases and H3K27me3 levels reduce during long-term genistein exposure (a) Western blot analysis was used to determine phospho-EZH2(Ser21), EZH2 and H3K27me3 levels at 2 days, 1 week, 2 weeks and 3 weeks after treatment with $1 \mu$ M TAM in T47D cells. (b) Western blot analysis was used to determine phospho-EZH2(Ser21), EZH2 and H3K27me3 levels at 2 days, 1 week, 2 weeks and 3 weeks after exposure to $1 \mu \mathrm{M}$ genistein or $1 \mathrm{nM}$ E2 in T47D cells. (c) Western blot analysis was used to determine phospho-EZH2(Ser21), EZH2 and H3K27me3 levels at 3 weeks after exposure to $1 \mu \mathrm{M}$ genistein in MCF-7 cells. 
a

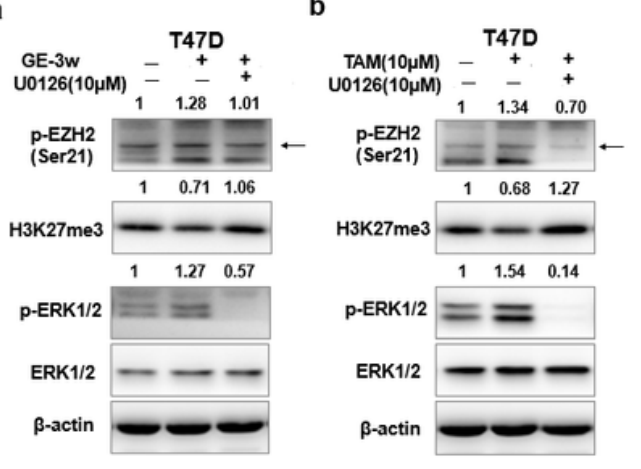

c

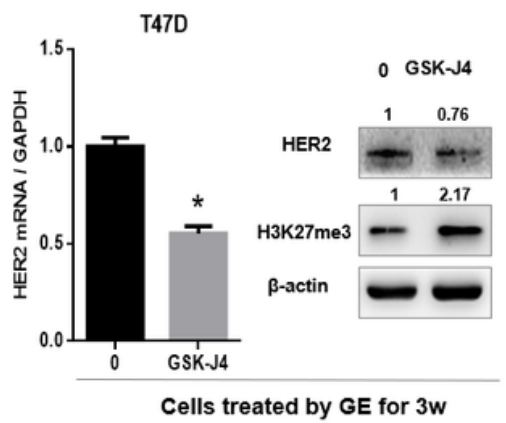

d

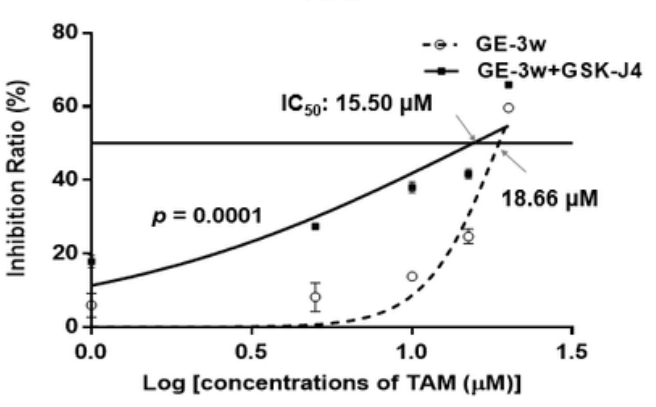

e
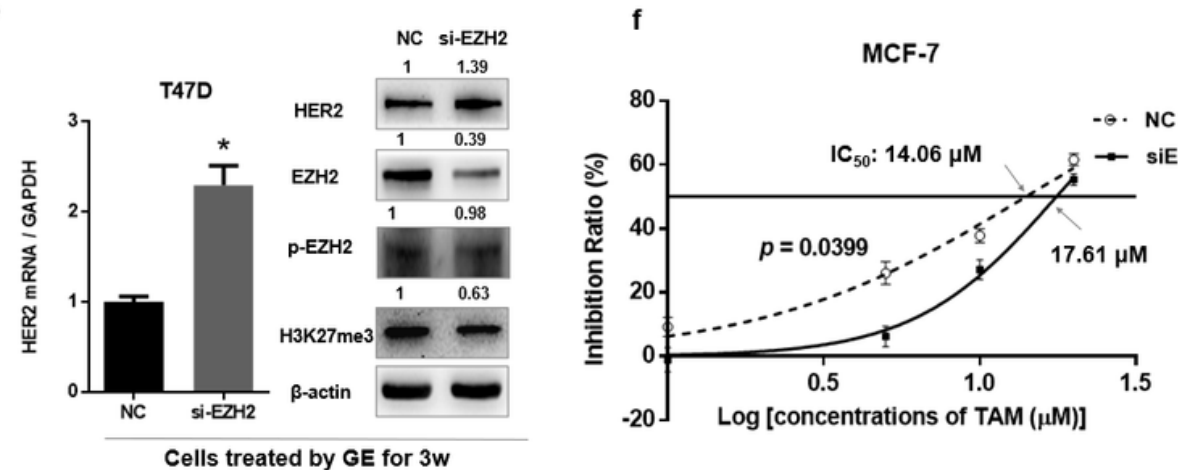

T47D

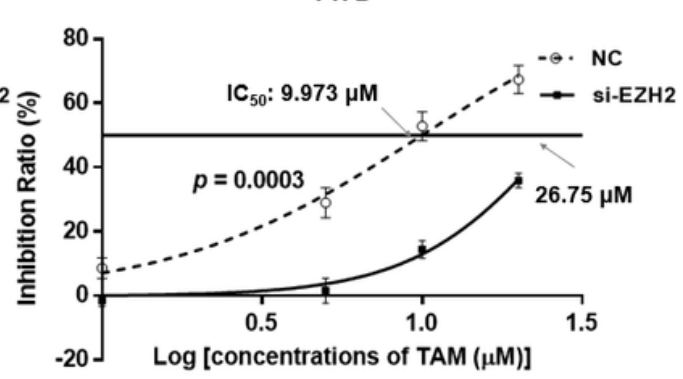

Figure 4

ERK1/2 signaling phosphorylates EZH2 and reduces H3K27me3 level associated with HER2 expression and endocrine resistance (a) Western blot analysis was used to determine phospho-EZH2(Ser21), H3K27me3, phospho-ERK1/2 and ERK1/2 levels at 24h after treatment with $10 \mu \mathrm{M}$ U0126 in T47D cells after 3 weeks with genistein. (b) Western blot analysis was performed to determine phosphoEZH2(Ser21), H3K27me3, phospho-ERK1/2 and ERK1/2 level at 24h after treatment with $10 \mu \mathrm{M}$ TAM alone or in combination with $10 \mu \mathrm{M} U 0126$ in T47D cells. (c) The mRNA levels of HER2 and the protein levels of HER2 and H3K27me3 were measured in T47D cells treated by $1 \mu \mathrm{M}$ genistein for 3 weeks, then treated with GSK-J4 for $12 \mathrm{~h}$. (d) After exposure to $1 \mu \mathrm{M}$ genistein for 3 weeks, genistein was removed, and T47D cells were treated with $5 \mu \mathrm{M}$ GSK-J4 for $12 \mathrm{~h}$, then treated with TAM $(1 \mu \mathrm{M}-20 \mu \mathrm{M})$ for $48 \mathrm{~h}$. The cell viability was determined by CCK8 assay in quadruplicate. (e) The mRNA levels of HER2 were assessed by PCR and the protein levels of HER2, EZH2 and H3K27me3 were measured by western blot analysis in T47D cells treated by $1 \mu \mathrm{M}$ genistein for 3 weeks, then transfected with EZH2 siRNA for $6 \mathrm{~h}$. (f) T47D cells were transfected with EZH2 siRNA, then treated with TAM $(1 \mu \mathrm{M}-20 \mu \mathrm{M})$ for $48 \mathrm{~h}$. The cell viability was determined by CCK8 assay in quadruplicate, and the IC50s were calculated. Data of the mRNA are expressed as the mean $\pm S D(n=3)$, ${ }^{*}<0.05$ vs. control group. 
a

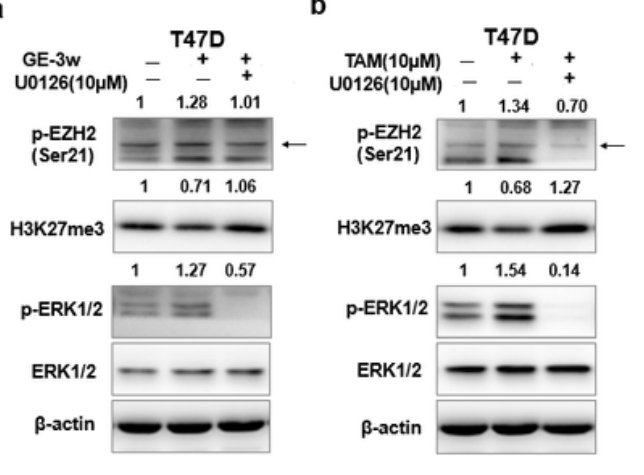

C

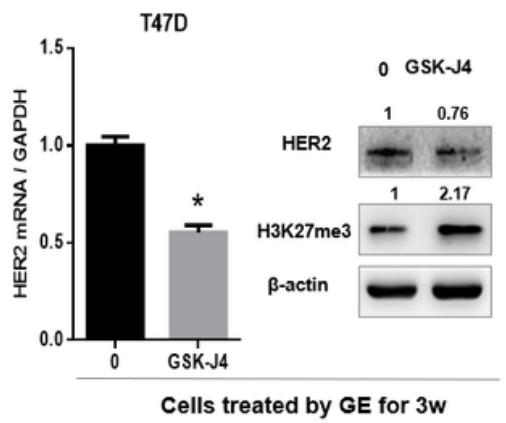

d

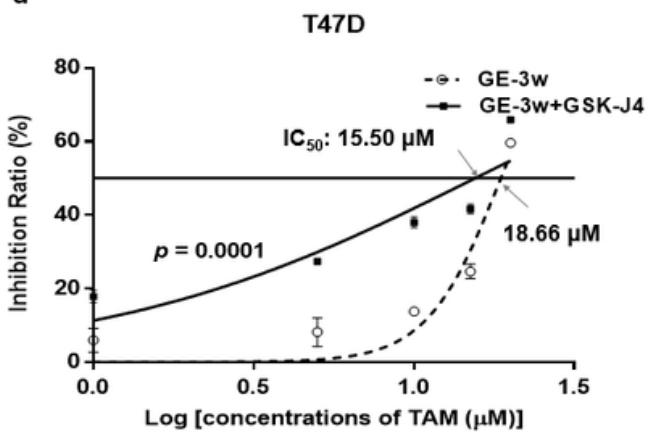

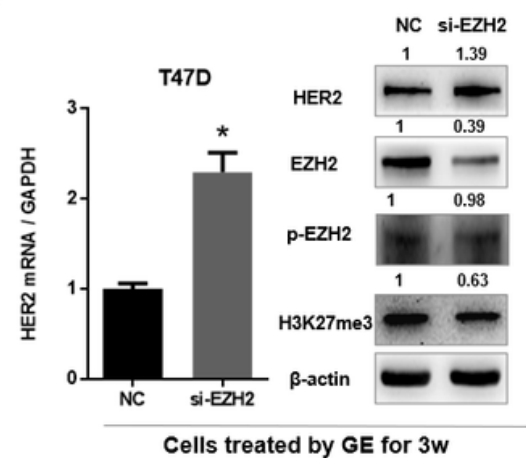

MCF-7

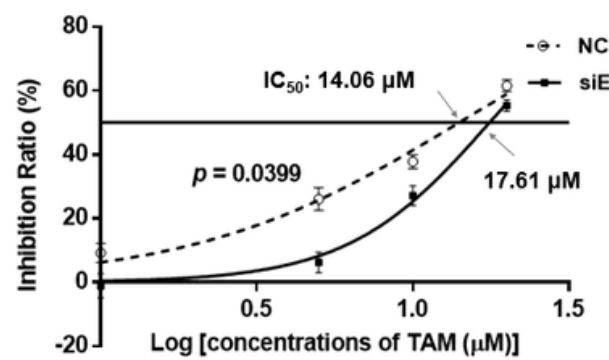

T47D

\section{Figure 4}

ERK1/2 signaling phosphorylates EZH2 and reduces H3K27me3 level associated with HER2 expression and endocrine resistance (a) Western blot analysis was used to determine phospho-EZH2(Ser21), H3K27me3, phospho-ERK1/2 and ERK1/2 levels at 24h after treatment with $10 \mu \mathrm{M}$ U0126 in T47D cells after 3 weeks with genistein. (b) Western blot analysis was performed to determine phosphoEZH2(Ser21), H3K27me3, phospho-ERK1/2 and ERK1/2 level at 24h after treatment with $10 \mu \mathrm{M}$ TAM alone or in combination with $10 \mu \mathrm{M} U 0126$ in T47D cells. (c) The mRNA levels of HER2 and the protein levels of HER2 and H3K27me3 were measured in T47D cells treated by $1 \mu \mathrm{M}$ genistein for 3 weeks, then treated with GSK-J4 for $12 \mathrm{~h}$. (d) After exposure to $1 \mu \mathrm{M}$ genistein for 3 weeks, genistein was removed, and T47D cells were treated with $5 \mu \mathrm{M}$ GSK-J4 for $12 \mathrm{~h}$, then treated with TAM $(1 \mu \mathrm{M}-20 \mu \mathrm{M})$ for $48 \mathrm{~h}$. The cell viability was determined by CCK8 assay in quadruplicate. (e) The mRNA levels of HER2 were assessed by PCR and the protein levels of HER2, EZH2 and H3K27me3 were measured by western blot analysis in T47D cells treated by $1 \mu \mathrm{M}$ genistein for 3 weeks, then transfected with EZH2 siRNA for $6 \mathrm{~h}$. (f) T47D cells were transfected with EZH2 siRNA, then treated with TAM $(1 \mu \mathrm{M}-20 \mu \mathrm{M})$ for $48 \mathrm{~h}$. The cell viability was determined by CCK8 assay in quadruplicate, and the IC50s were calculated. Data of the mRNA are expressed as the mean $\pm S D(n=3)$, ${ }^{*}<0.05$ vs. control group. 
a

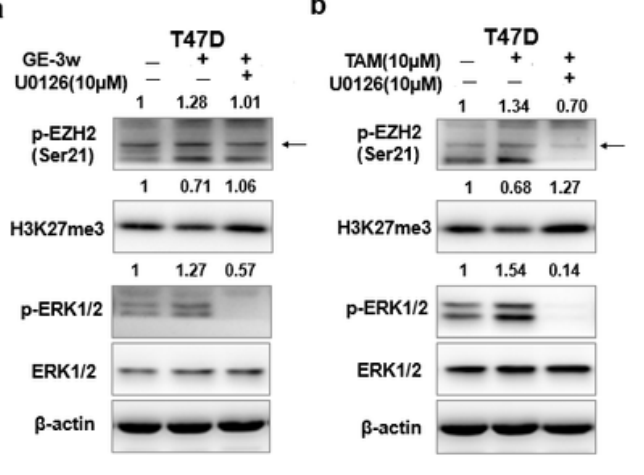

C

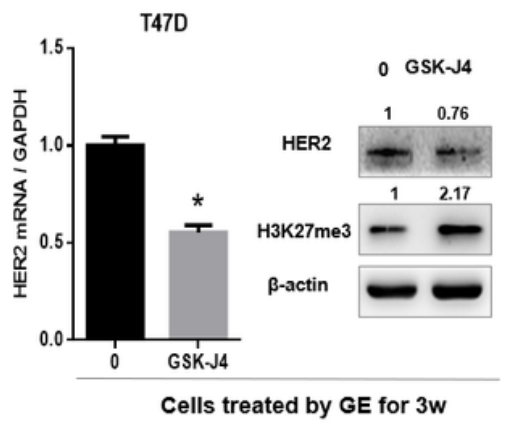

d

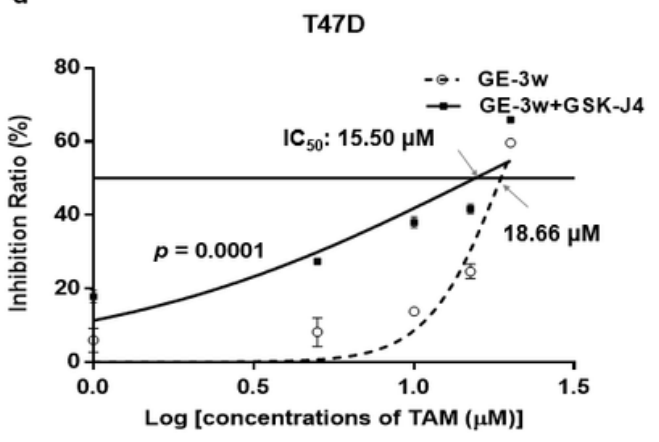

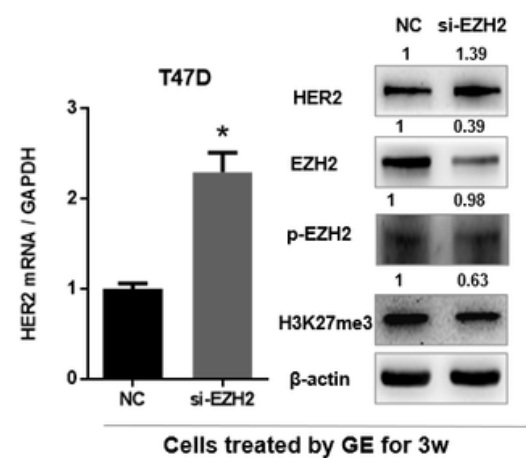

MCF-7

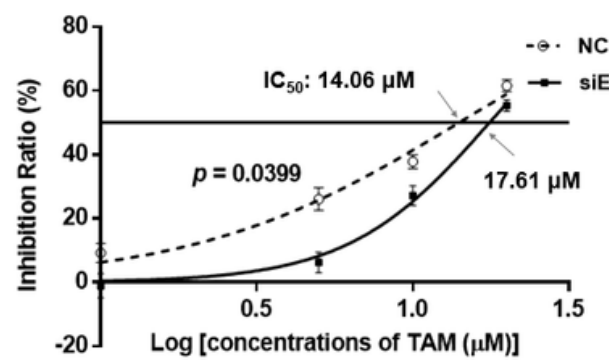

T47D

\section{Figure 4}

ERK1/2 signaling phosphorylates EZH2 and reduces H3K27me3 level associated with HER2 expression and endocrine resistance (a) Western blot analysis was used to determine phospho-EZH2(Ser21), H3K27me3, phospho-ERK1/2 and ERK1/2 levels at 24h after treatment with $10 \mu \mathrm{M}$ U0126 in T47D cells after 3 weeks with genistein. (b) Western blot analysis was performed to determine phosphoEZH2(Ser21), H3K27me3, phospho-ERK1/2 and ERK1/2 level at 24h after treatment with $10 \mu \mathrm{M}$ TAM alone or in combination with $10 \mu \mathrm{M} U 0126$ in T47D cells. (c) The mRNA levels of HER2 and the protein levels of HER2 and H3K27me3 were measured in T47D cells treated by $1 \mu \mathrm{M}$ genistein for 3 weeks, then treated with GSK-J4 for $12 \mathrm{~h}$. (d) After exposure to $1 \mu \mathrm{M}$ genistein for 3 weeks, genistein was removed, and T47D cells were treated with $5 \mu \mathrm{M}$ GSK-J4 for $12 \mathrm{~h}$, then treated with TAM $(1 \mu \mathrm{M}-20 \mu \mathrm{M})$ for $48 \mathrm{~h}$. The cell viability was determined by CCK8 assay in quadruplicate. (e) The mRNA levels of HER2 were assessed by PCR and the protein levels of HER2, EZH2 and H3K27me3 were measured by western blot analysis in T47D cells treated by $1 \mu \mathrm{M}$ genistein for 3 weeks, then transfected with EZH2 siRNA for $6 \mathrm{~h}$. (f) T47D cells were transfected with EZH2 siRNA, then treated with TAM $(1 \mu \mathrm{M}-20 \mu \mathrm{M})$ for $48 \mathrm{~h}$. The cell viability was determined by CCK8 assay in quadruplicate, and the IC50s were calculated. Data of the mRNA are expressed as the mean $\pm S D(n=3)$, ${ }^{*}<0.05$ vs. control group. 
a

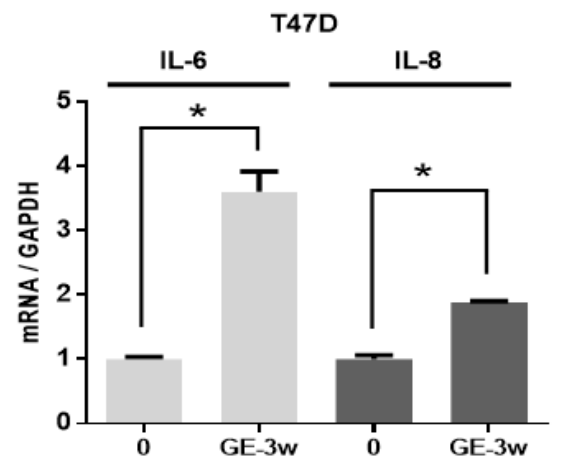

b

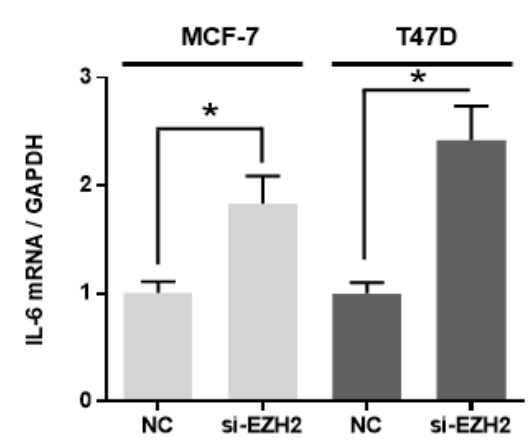

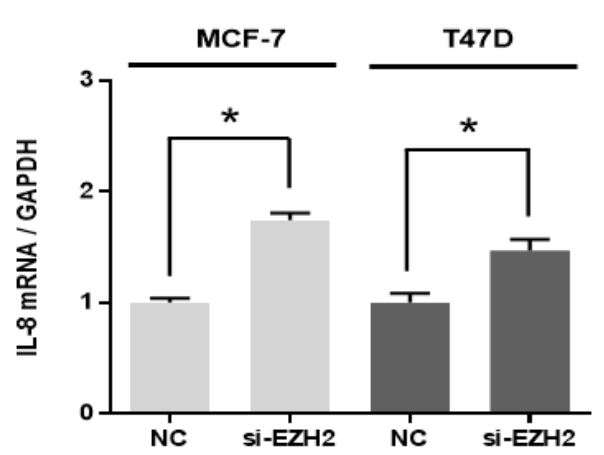

C

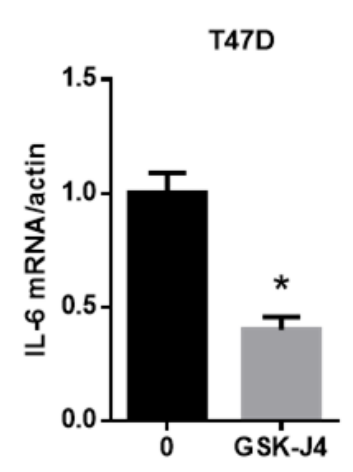

T47D

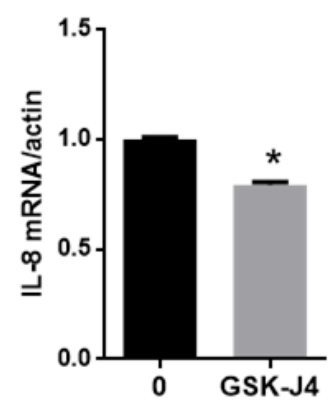

d

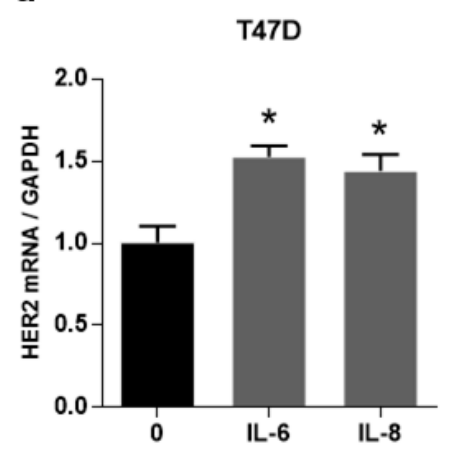

T47D

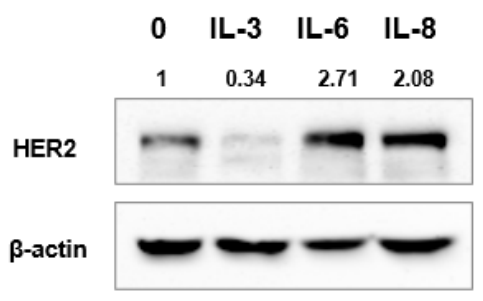

e

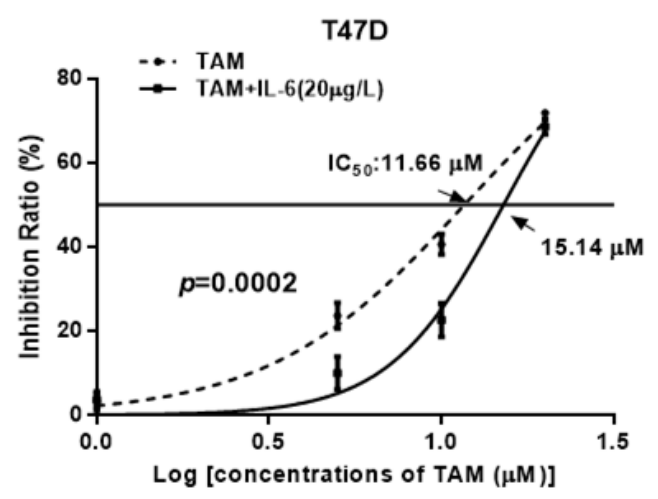

$\mathbf{f}$

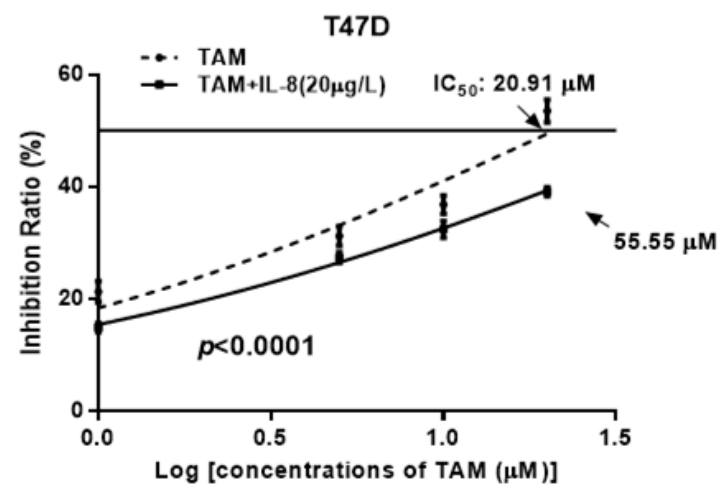

\section{Figure 5}

Increased IL-6 and IL-8 induced by genistein is involved in HER2 elevation and endocrine resistance (a) The mRNA levels of IL- 6 and IL-8 were assessed by PCR in T47D cells treated with $1 \mu \mathrm{M}$ genistein for 3 weeks. (b) The mRNA levels of IL- 6 and IL-8 were assessed by PCR in MCF-7 cells and T47D cells transfected with EZH2 siRNA for $6 \mathrm{~h}$. (c) The mRNA levels of IL-6 and IL-8 were assessed by PCR in T47D cells treated with $5 \mu \mathrm{M}$ GSK-J4 for $12 \mathrm{~h}$. Data of the mRNA are expressed as the mean \pm SD $(n=3)$, *p < 0.05 vs. control group. (d) The mRNA levels of HER2 were assessed by PCR and the protein levels of HER2 were measured by western blot analysis in T47D cells treated with IL-6 $(20 \mu \mathrm{g} / \mathrm{L})$ or IL-8 $(20 \mu \mathrm{g} / \mathrm{L})$ for $24 \mathrm{~h}$. (e) T47D cells were treated with $20 \mu \mathrm{g} / \mathrm{L} \mathrm{IL}-6$ for $24 \mathrm{~h}$, and then treated with TAM $(1 \mu \mathrm{M}-20 \mu \mathrm{M})$ for 48h. (f) T47D cells were treated with $20 \mu \mathrm{g} / \mathrm{L}$ IL-8 for $24 \mathrm{~h}$, and then treated with TAM $(1 \mu \mathrm{M}-20 \mu \mathrm{M})$ for $48 \mathrm{~h}$. The cell viability was determined by CCK8 assay in quadruplicate, and the IC50s were calculated. Data of the mRNA are expressed as the mean \pm SD $(n=3),{ }^{*} p<0.05$ vs. control group. 
a

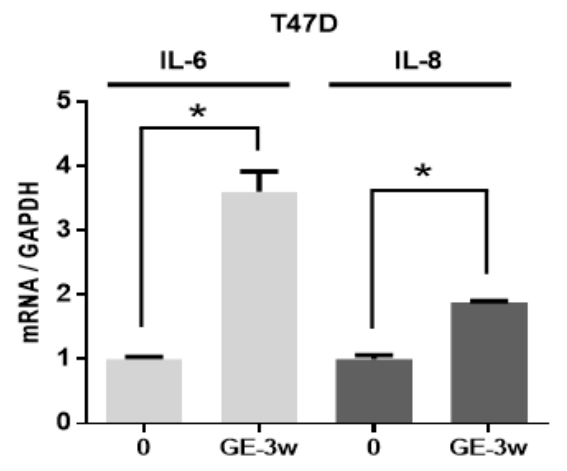

b

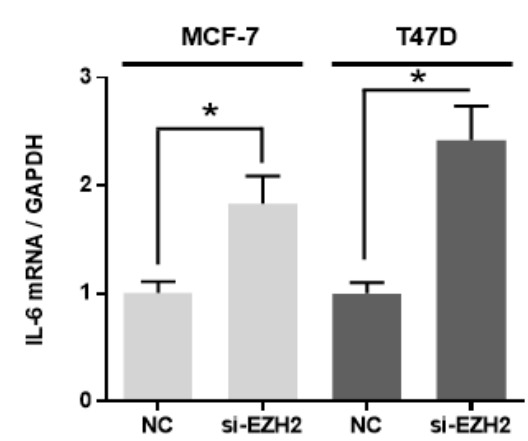

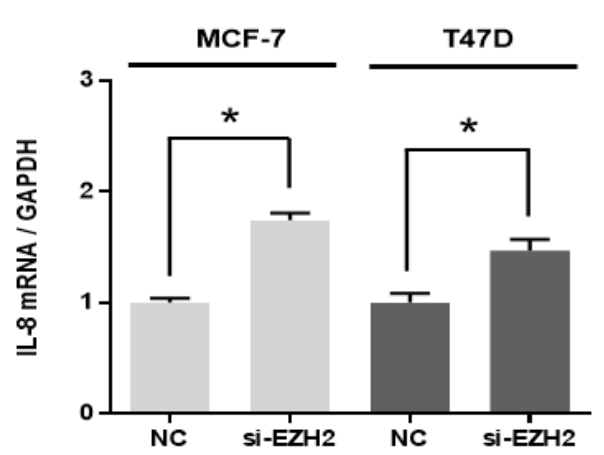

C

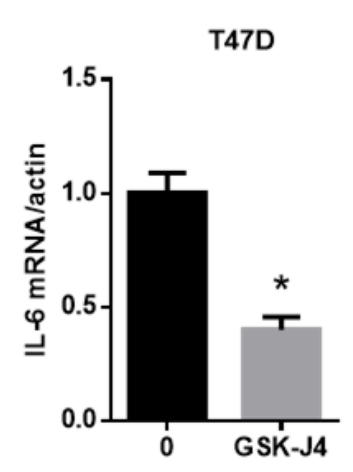

T47D

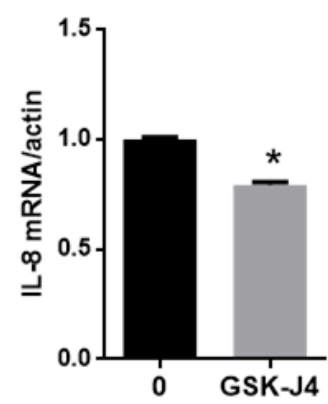

d

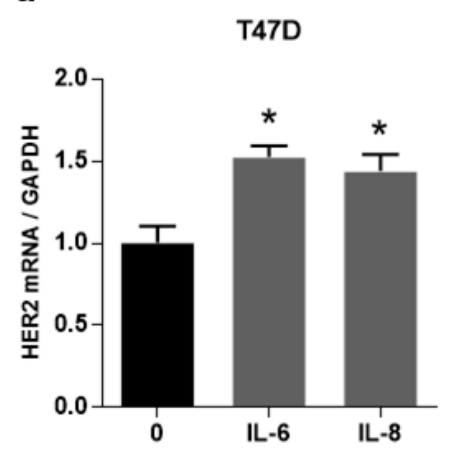

T47D

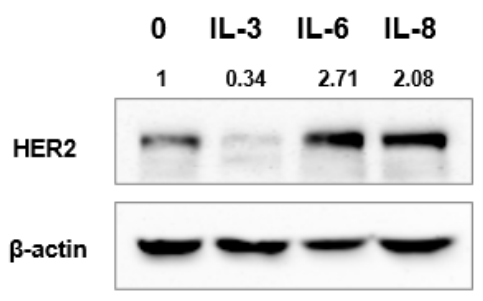

e

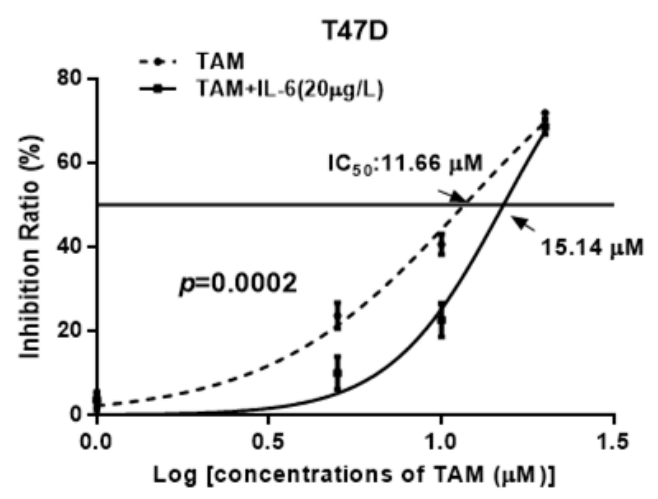

$\mathbf{f}$

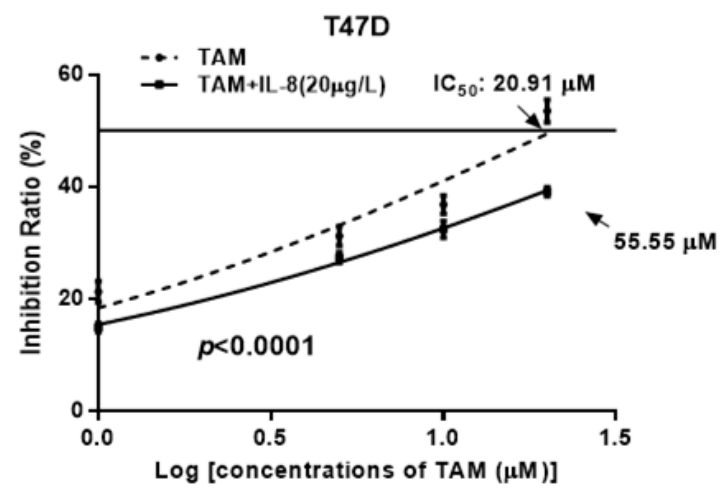

\section{Figure 5}

Increased IL-6 and IL-8 induced by genistein is involved in HER2 elevation and endocrine resistance (a) The mRNA levels of IL- 6 and IL-8 were assessed by PCR in T47D cells treated with $1 \mu \mathrm{M}$ genistein for 3 weeks. (b) The mRNA levels of IL- 6 and IL-8 were assessed by PCR in MCF-7 cells and T47D cells transfected with EZH2 siRNA for $6 \mathrm{~h}$. (c) The mRNA levels of IL-6 and IL-8 were assessed by PCR in T47D cells treated with $5 \mu \mathrm{M}$ GSK-J4 for $12 \mathrm{~h}$. Data of the mRNA are expressed as the mean \pm SD $(n=3)$, *p < 0.05 vs. control group. (d) The mRNA levels of HER2 were assessed by PCR and the protein levels of HER2 were measured by western blot analysis in T47D cells treated with IL-6 $(20 \mu \mathrm{g} / \mathrm{L})$ or IL-8 $(20 \mu \mathrm{g} / \mathrm{L})$ for $24 \mathrm{~h}$. (e) T47D cells were treated with $20 \mu \mathrm{g} / \mathrm{L} \mathrm{IL}-6$ for $24 \mathrm{~h}$, and then treated with TAM $(1 \mu \mathrm{M}-20 \mu \mathrm{M})$ for 48h. (f) T47D cells were treated with $20 \mu \mathrm{g} / \mathrm{L}$ IL-8 for $24 \mathrm{~h}$, and then treated with TAM $(1 \mu \mathrm{M}-20 \mu \mathrm{M})$ for $48 \mathrm{~h}$. The cell viability was determined by CCK8 assay in quadruplicate, and the IC50s were calculated. Data of the mRNA are expressed as the mean \pm SD $(n=3),{ }^{*} p<0.05$ vs. control group. 
a

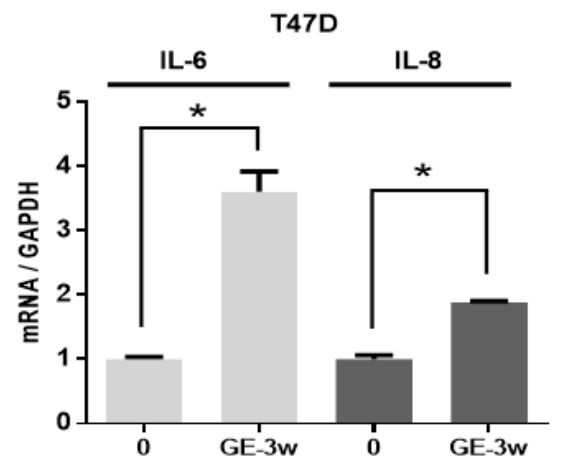

b

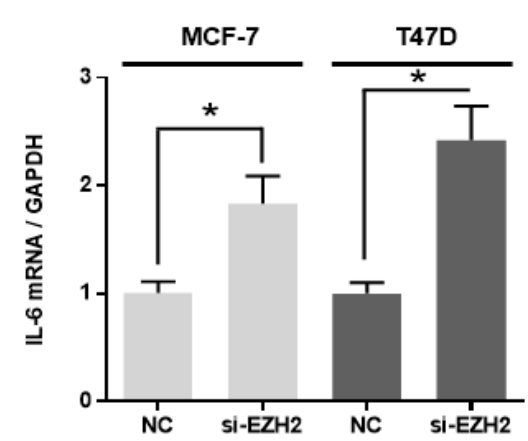

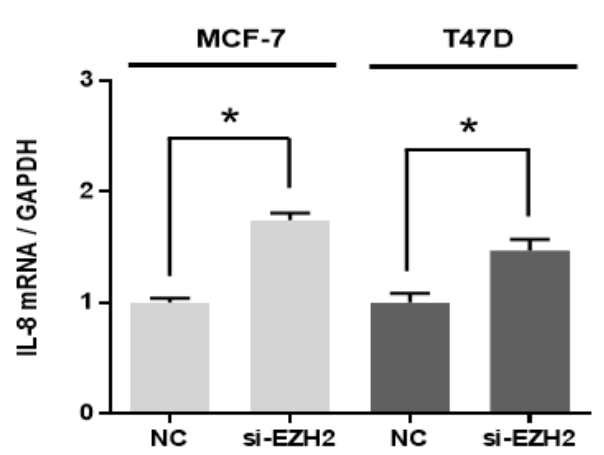

C

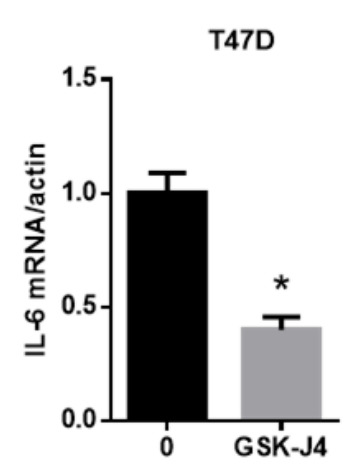

T47D

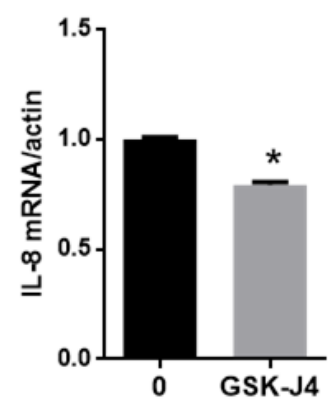

d

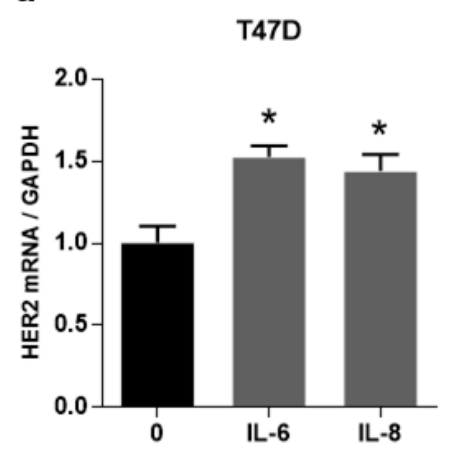

T47D

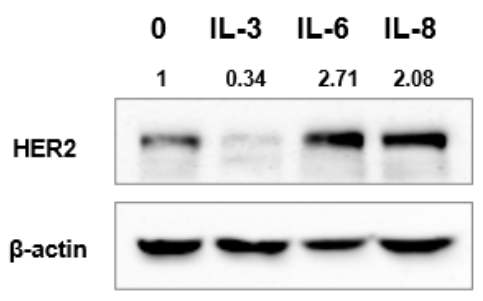

e

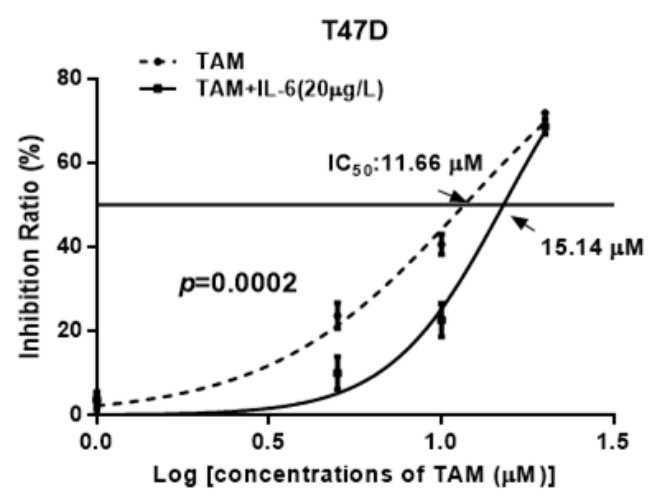

$\mathbf{f}$

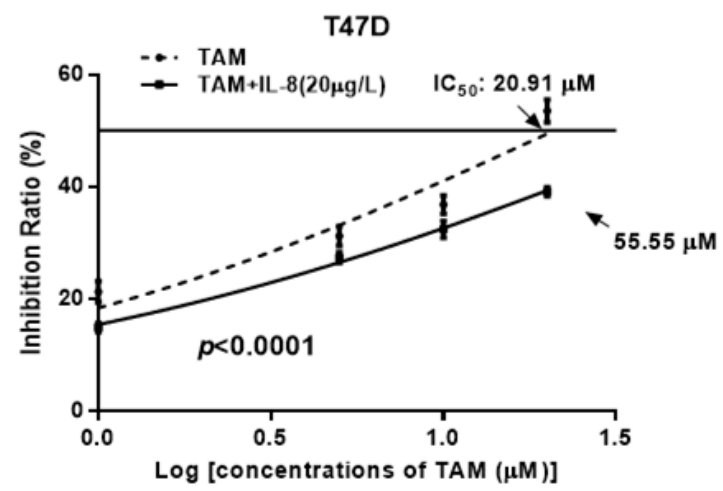

\section{Figure 5}

Increased IL-6 and IL-8 induced by genistein is involved in HER2 elevation and endocrine resistance (a) The mRNA levels of IL- 6 and IL-8 were assessed by PCR in T47D cells treated with $1 \mu \mathrm{M}$ genistein for 3 weeks. (b) The mRNA levels of IL- 6 and IL-8 were assessed by PCR in MCF-7 cells and T47D cells transfected with EZH2 siRNA for $6 \mathrm{~h}$. (c) The mRNA levels of IL-6 and IL-8 were assessed by PCR in T47D cells treated with $5 \mu \mathrm{M}$ GSK-J4 for $12 \mathrm{~h}$. Data of the mRNA are expressed as the mean \pm SD $(n=3)$, *p < 0.05 vs. control group. (d) The mRNA levels of HER2 were assessed by PCR and the protein levels of HER2 were measured by western blot analysis in T47D cells treated with IL-6 $(20 \mu \mathrm{g} / \mathrm{L})$ or IL-8 $(20 \mu \mathrm{g} / \mathrm{L})$ for $24 \mathrm{~h}$. (e) T47D cells were treated with $20 \mu \mathrm{g} / \mathrm{L} \mathrm{IL}-6$ for $24 \mathrm{~h}$, and then treated with TAM $(1 \mu \mathrm{M}-20 \mu \mathrm{M})$ for 48h. (f) T47D cells were treated with $20 \mu \mathrm{g} / \mathrm{L} \mathrm{IL}-8$ for $24 \mathrm{~h}$, and then treated with TAM $(1 \mu \mathrm{M}-20 \mu \mathrm{M})$ for $48 \mathrm{~h}$. The cell viability was determined by CCK8 assay in quadruplicate, and the IC50s were calculated. Data of the mRNA are expressed as the mean \pm SD $(n=3),{ }^{*} p<0.05$ vs. control group. 
a

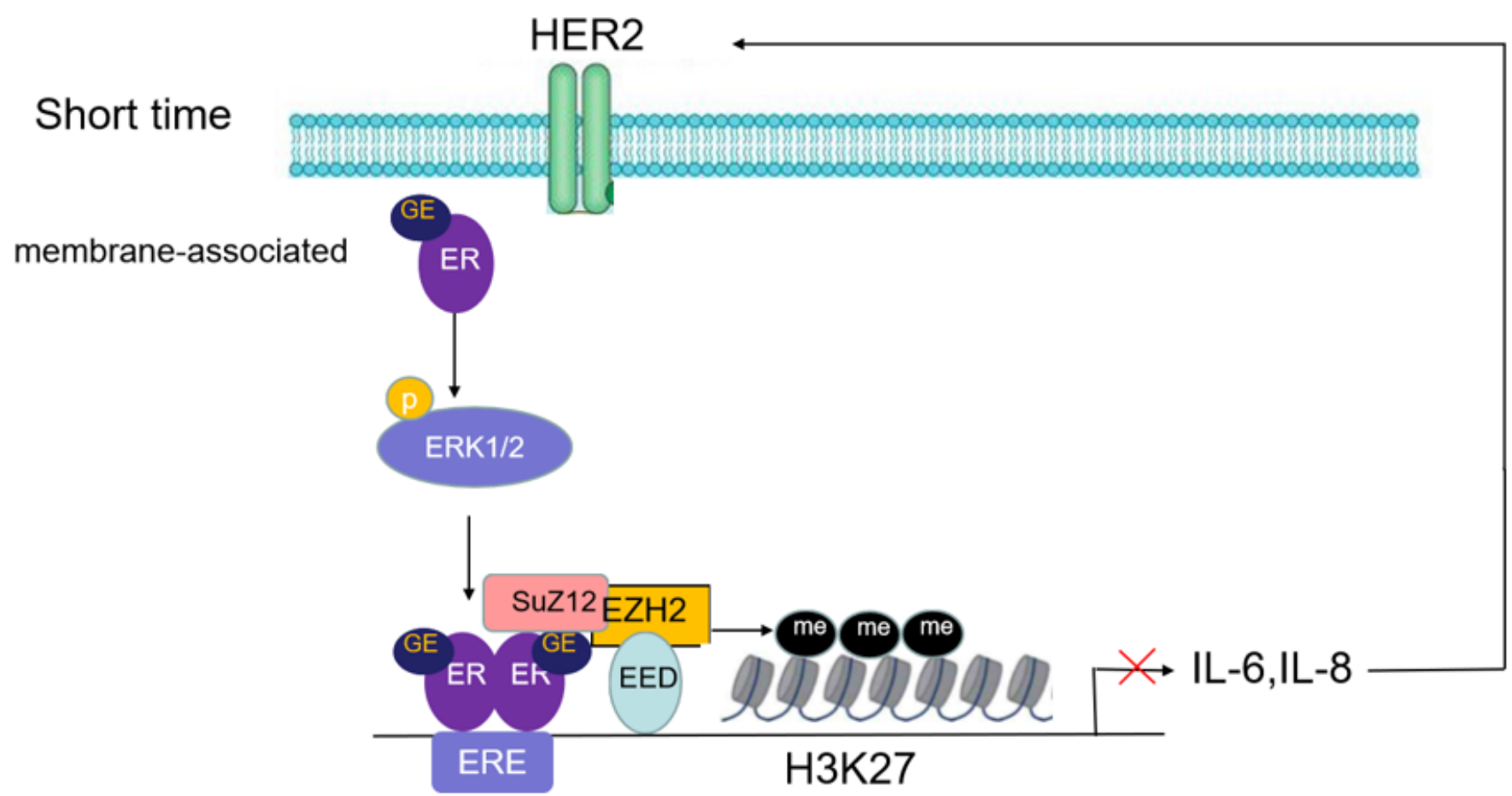

b

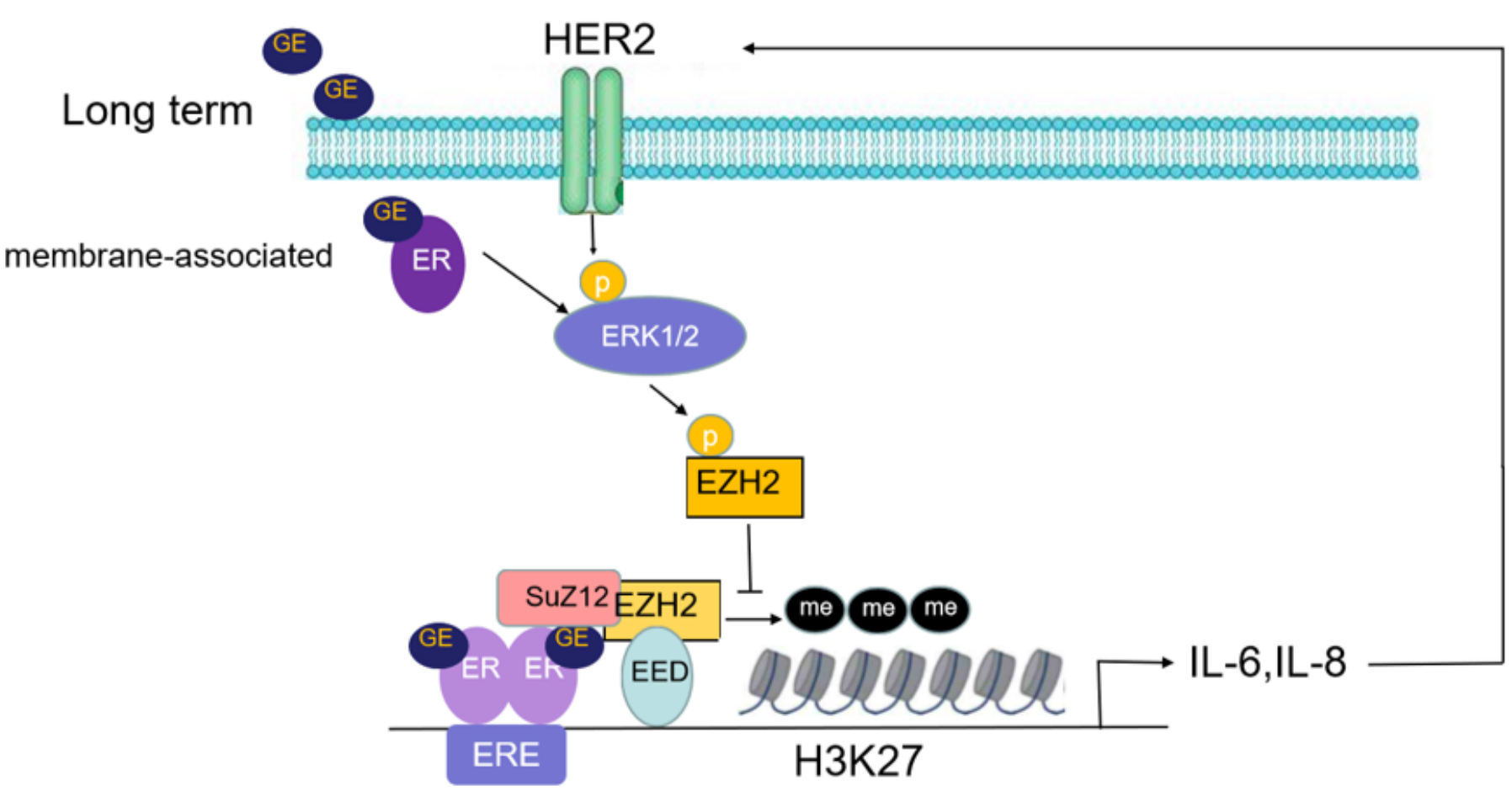

\section{Figure 6}

Role of EZH2 in expression of HER2 mediated by genistein in ER -positive breast cancer cells (a) Genistein plays an estrogen-like role in short-term exposure. In the cytoplasm, genistein binds to ER, rapidly activates ERK1/2 signaling and enhances the nuclear transcription function of ER, thereby promoting the expression of EZH2 and enhancing the histone methylation function. H3K27me3 inhibits the expression of IL-6 and IL-8, and thus inhibits the expression of HER2. (b) After long-term exposure 
with genistein, the continuous activation of ERK1/2 signal leads to phosphorylation of EZH2 Ser21, resulting in decrease of H3K27me3 level, which alleviates its inhibitory effect on IL-6 and IL-8. II-6 and IL-8 increase HER2 level, and HER2 further activates ERK1/2 signal, forming the feedback loop of ERK1/2 / EZH2/H3K27me3/ IL-6 and IL-8/ HER2.

a

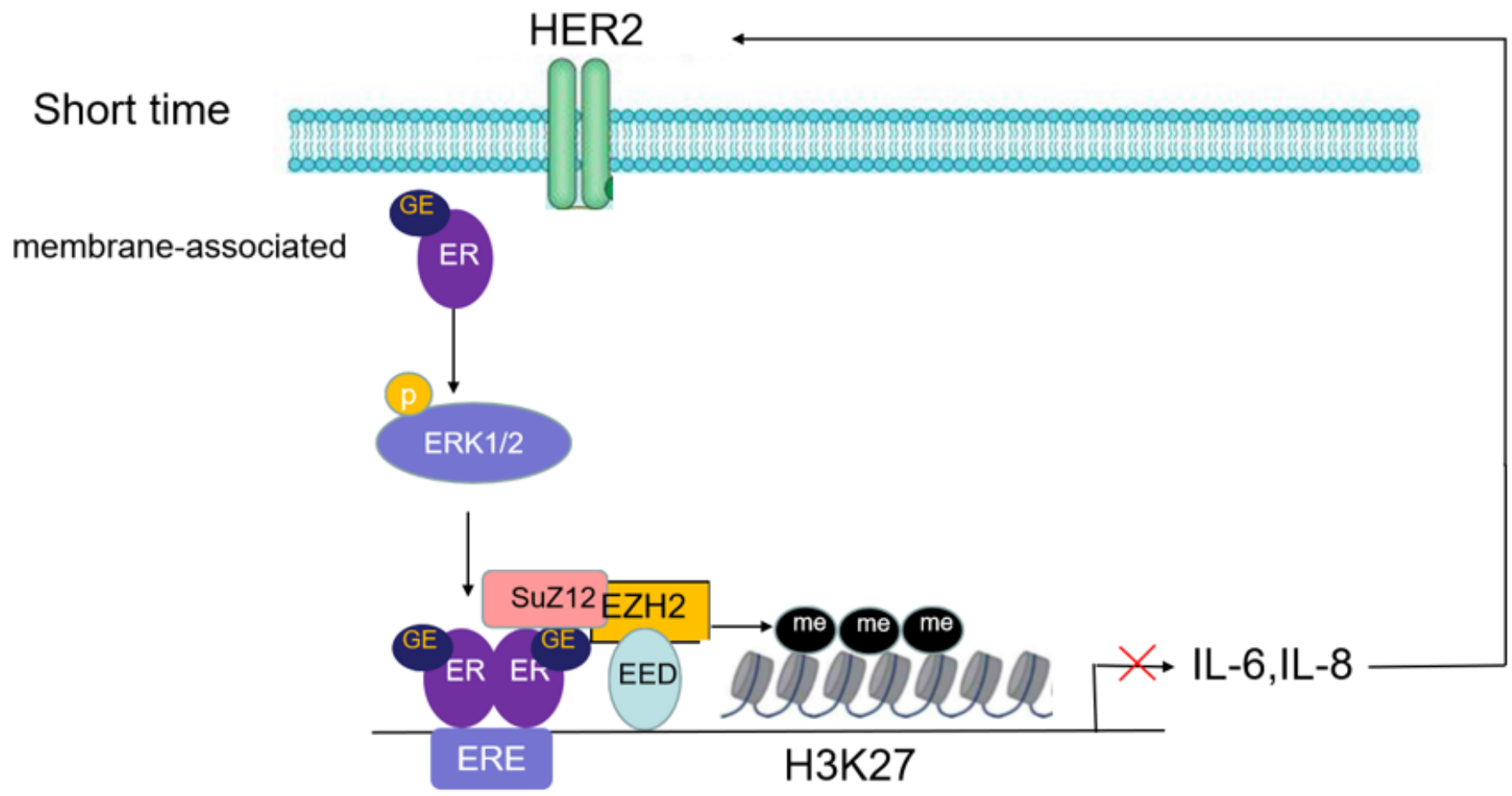

b

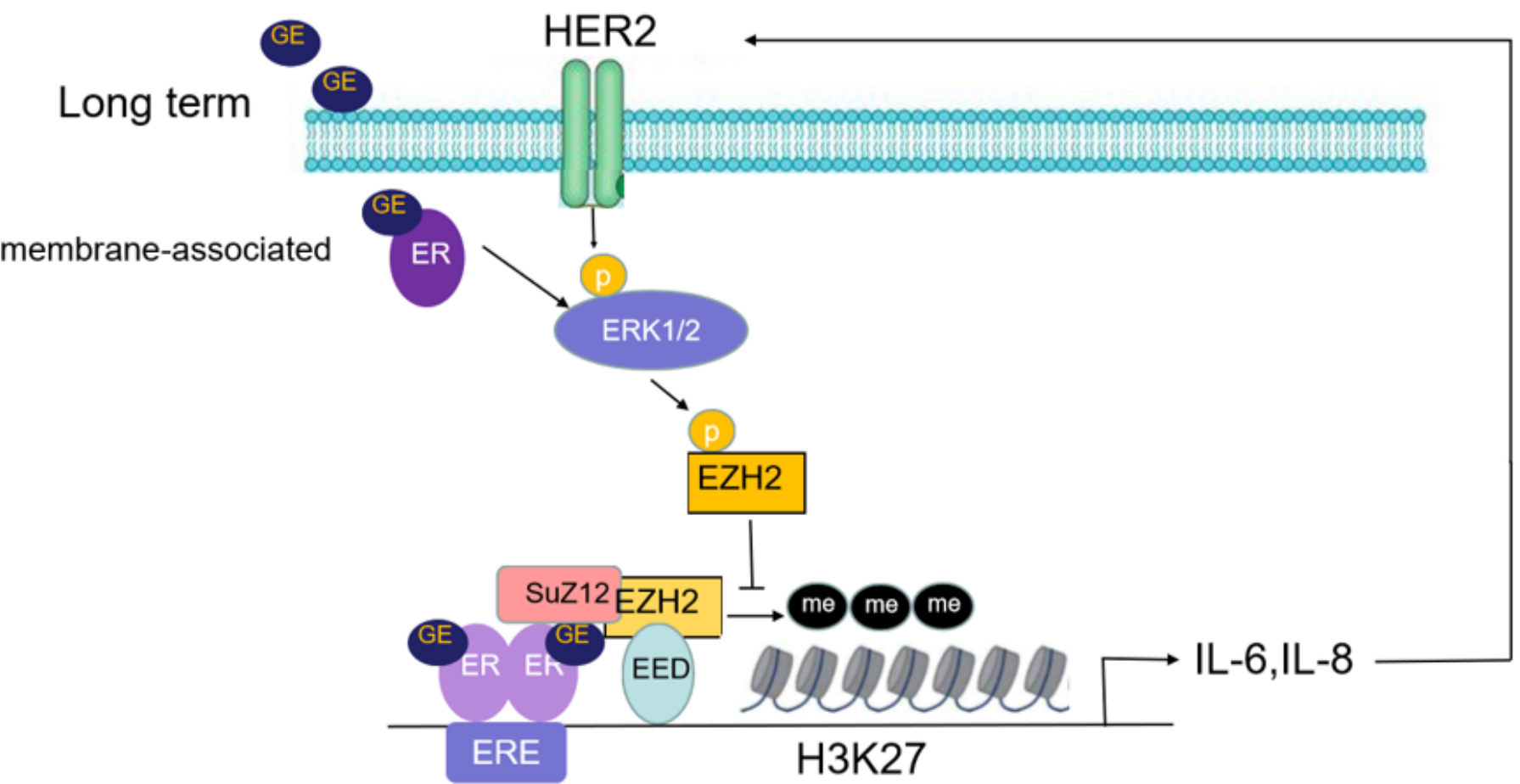

Figure 6 
Role of EZH2 in expression of HER2 mediated by genistein in ER -positive breast cancer cells (a) Genistein plays an estrogen-like role in short-term exposure. In the cytoplasm, genistein binds to ER, rapidly activates ERK1/2 signaling and enhances the nuclear transcription function of ER, thereby promoting the expression of EZH2 and enhancing the histone methylation function. H3K27me3 inhibits the expression of IL-6 and IL-8, and thus inhibits the expression of HER2. (b) After long-term exposure with genistein, the continuous activation of ERK1/2 signal leads to phosphorylation of EZH2 Ser21, resulting in decrease of H3K27me3 level, which alleviates its inhibitory effect on IL-6 and IL-8. II- 6 and IL-8 increase HER2 level, and HER2 further activates ERK1/2 signal, forming the feedback loop of ERK1/2 / EZH2/H3K27me3/ IL-6 and IL-8/ HER2. 
a

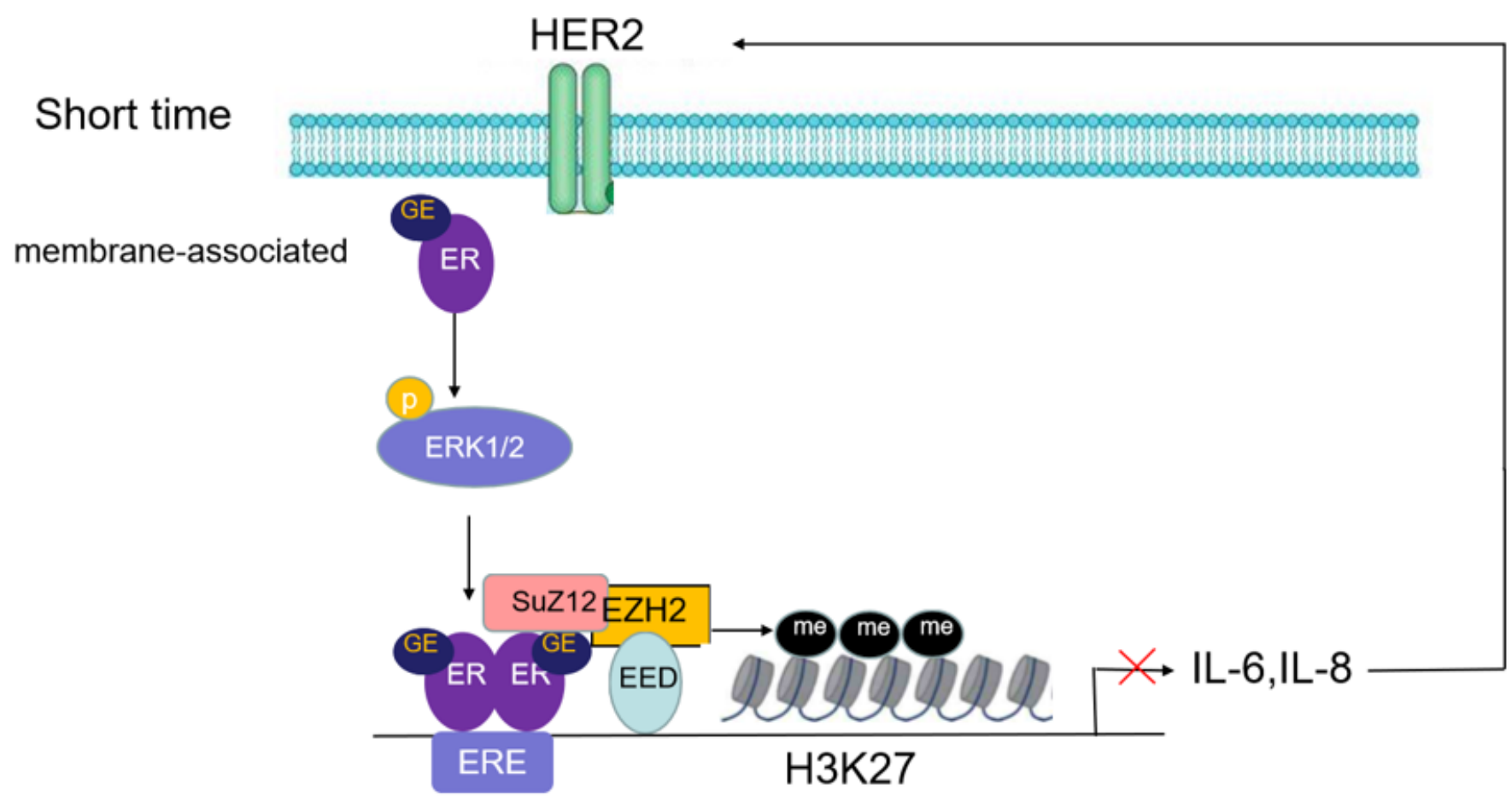

b

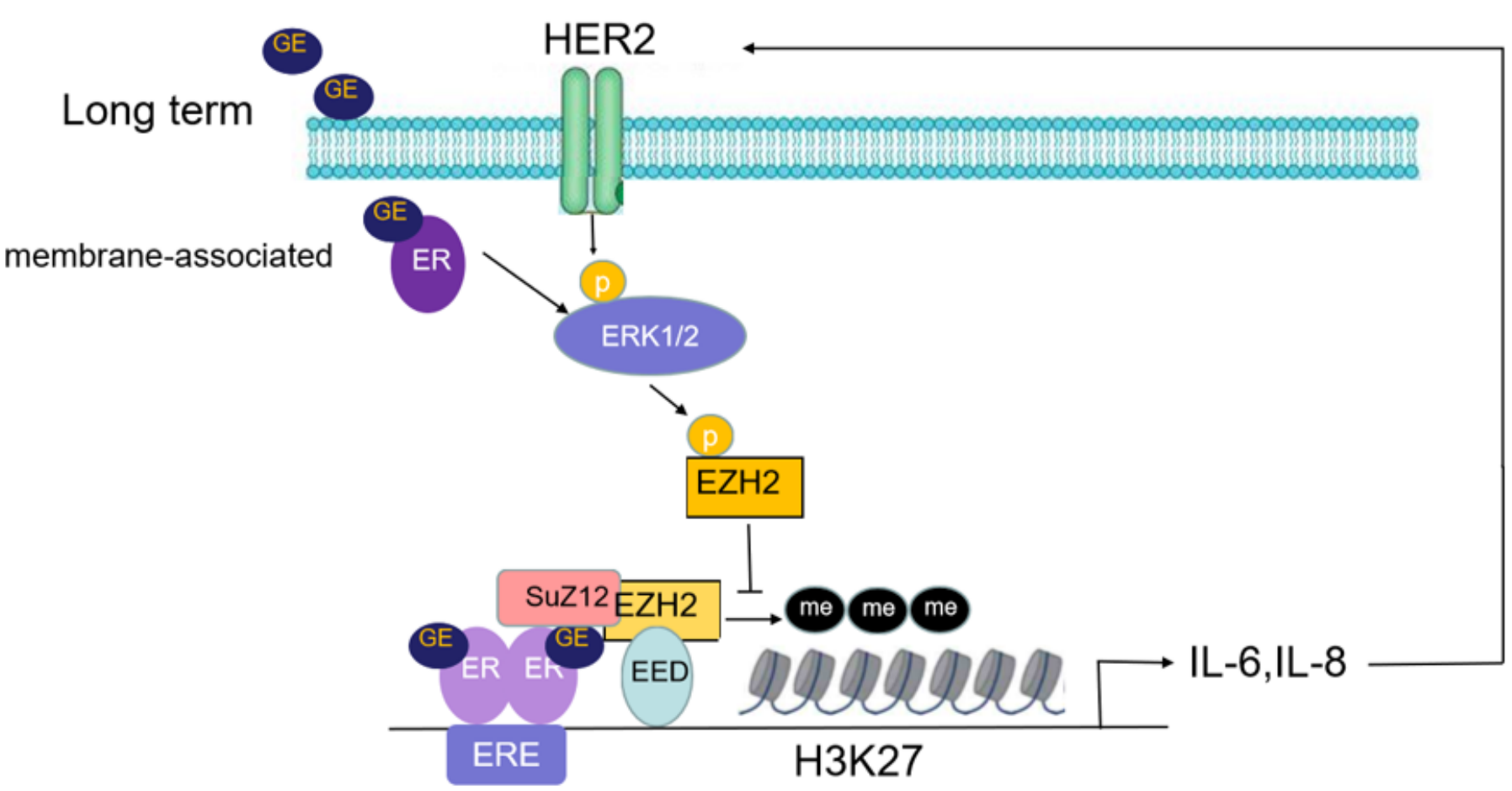

\section{Figure 6}

Role of EZH2 in expression of HER2 mediated by genistein in ER -positive breast cancer cells (a) Genistein plays an estrogen-like role in short-term exposure. In the cytoplasm, genistein binds to ER, rapidly activates ERK1/2 signaling and enhances the nuclear transcription function of ER, thereby promoting the expression of EZH2 and enhancing the histone methylation function. H3K27me3 inhibits the expression of IL-6 and IL-8, and thus inhibits the expression of HER2. (b) After long-term exposure 
with genistein, the continuous activation of ERK1/2 signal leads to phosphorylation of EZH2 Ser21, resulting in decrease of H3K27me3 level, which alleviates its inhibitory effect on IL- 6 and IL-8. II- 6 and IL-8 increase HER2 level, and HER2 further activates ERK1/2 signal, forming the feedback loop of ERK1/2 / EZH2/H3K27me3/ IL-6 and IL-8/ HER2.

\section{Supplementary Files}

This is a list of supplementary files associated with this preprint. Click to download.

- Additionalfile.pdf

- Additionalfile.pdf

- Additionalfile.pdf 